\title{
Echocardiography in patients with hypertrophic cardiomyopathy: usefulness of old and new techniques in the diagnosis and pathophysiological assessment
}

\author{
Maria-Angela Losi ${ }^{1 *}$, Stefano Nistri ${ }^{2}$, Maurizio Galderisi ${ }^{3}$, Sandro Betocchi ${ }^{1}$, Franco Cecchi ${ }^{4}$, lacopo Olivotto ${ }^{4}$, \\ Eustachio Agricola ${ }^{5}$, Piercarlo Ballo ${ }^{6}$, Simona Buralli ${ }^{7}$, Antonello D'Andrea ${ }^{8}$, Arcangelo D'Errico ${ }^{3}$, Donato Mele ${ }^{9}$, \\ Susanna Sciomer ${ }^{10}$, Sergio Mondillo ${ }^{10,11}$, the Working Group of Echocardiography of the Italian Society of \\ Cardiology
}

\begin{abstract}
Hypertrophic cardiomyopathy ( $\mathrm{HCM}$ ) is one of the most common inherited cardiomyopathy. The identification of patients with HCM is sometimes still a challenge. Moreover, the pathophysiology of the disease is complex because of left ventricular hyper-contractile state, diastolic dysfunction, ischemia and obstruction which can be coexistent in the same patient. In this review, we discuss the current and emerging echocardiographic methodology that can help physicians in the correct diagnostic and pathophysiological assessment of patients with HCM.
\end{abstract}

\section{Introduction}

Hypertrophic cardiomyopathy (HCM) is clinically defined in presence of left ventricular (LV) hypertrophy in the absence of hypertension and valve disease. LV hypertrophy without cardiovascular causes occurs in approximately 1:500 of the general population [1-3]. This incidence includes all kinds of hypertrophy not necessarily HCM, which is a familial disease with an autosomal dominant pattern of inheritance caused by mutations in genes encoding for sarcomeric proteins resulting usually in an asymmetrical pattern of LV hypertrophy. Echocardiography plays a pivotal role in detecting the disease and understanding its pathophysiology. In this review, we discuss the current and emerging echocardiographic methodology that can help physician in the correct diagnosis and pathophysiological assessment of patients with HCM.

\section{Echocardiography and Diagnosis}

Conventional Echocardiography

HCM may be initially suspected because of an heart murmur, positive family history, new symptoms or

\footnotetext{
* Correspondence: losi@unina.it

'Department of Clinical Medicine, Cardiovascular and Immunological Sciences, University Federico II, Naples, Italy
}

abnormal ECG pattern showing LV hypertrophy and abnormal Q waves. Thereafter an echocardiogram is usually performed.

\section{M-Mode Echocardiography}

The first echocardiographic diagnostic criteria in HCM were established by using $\mathrm{M}$-mode imaging which included asymmetrical septal hypertrophy, systolic anterior motion of the mitral valve (SAM), a small LV cavity, septal immobility, and premature closure of the aortic valve [1-3]. LV thickness, evaluated at septum and free wall level, is considered abnormal when $\geq 15 \mathrm{~mm}$, and defined asymmetrical in presence of a septal to free wall thickness ratio between 1.3 and 1.5. SAM is characterized by an abrupt anterior movement of the mitral valve reaching its peak before maximum movement of the posterior wall (Figure 1); this characteristic allows to differentiate true SAM from SAM produced by an exaggerated anterior motion of the mitral valve which reaches its peak after the fully contraction of the posterior wall, i.e. "pseudo SAM" [4]. There is a positive correlation between the severity of SAM and the severity of obstruction evaluated invasively [5]. Usually, a contact between SAM and the septum indicates an obstruction $\geq 30 \mathrm{mmHg}$. Moreover, the measurement of the time 


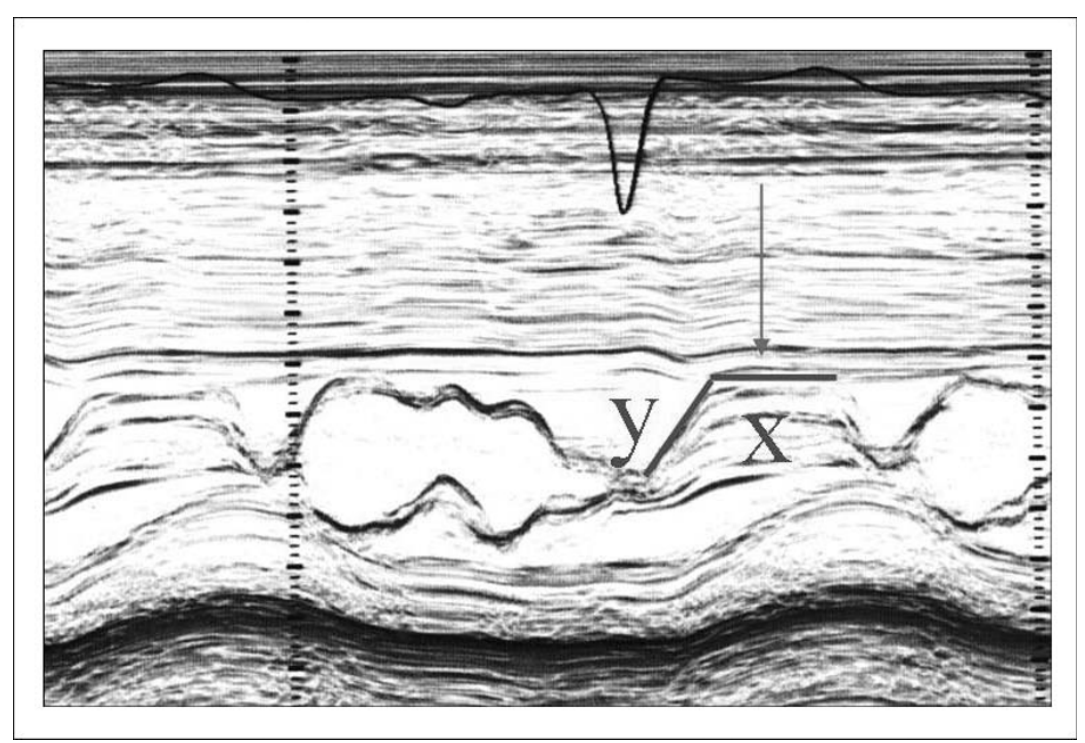

Figure 1 Systolic anterior motion (SAM) of the mitral valve visualized by M-Mode echocardiography. X represent the duration of SAM, whereas $Y$ represent the time elapsed between the beginning of SAM and the SAM-septal contact (see text for more details).

interval from the beginning of SAM to the SAM-septal contact $(\mathrm{y})$ and the duration of SAM-septal contact $(\mathrm{x})$ provides a reliable non-invasive method for estimation of the pressure gradient, where the gradient is $(\mathrm{x} / \mathrm{y}) * 25$ +25 mmHg (Figure 1) [5].

The movement of mitral valve is easily visualized by M-Mode and its anterior motion during systole, together with asymmetrical septal hypertrophy, was initially thought to be pathognomonic of HCM. However, these findings may be present in other forms of secondary and primary hypertrophy, like chronic systemic and reno-vascular hypertension [6], Fabry's disease $[7,8]$, glicogenosis [9], Friedreich ataxia [10], etc.

Left atrial (LA) diameter is usually increased in patients with HCM because of obstruction and/or diastolic dysfunction. LA diameter gives informations about the risk of atrial fibrillation, of heart failure development and of cardiac mortality [11] which is particularly high in patients with a LA diameter $>48 \mathrm{~mm}$. Finally, LA fractional shortening, evaluated as ([maximal diameterminimum diameter]/maximal diameter*100), is an estimate of end-diastolic pressure in HCM [12]; this parameter is directly related to exercise tolerance [13], and its reduction (i.e. $<16 \%)$ represents an independent risk factor for atrial fibrillation development [14].

\section{Two-dimensional echocardiography}

This technique by visualizing the whole heart has come the recognition that LV hypertrophy is most often asymmetrical and it can be confined in specific LV segments such as the apex.

\section{LV hypertrophy and function}

Currently, using short-axis view the left ventricle is divided in $4 \mathrm{LV}$ wall segments: anterior and posterior septum and posterior and lateral wall (Figure 2, left panel) [4]. Segments are visualized at mitral and papillary level, whereas the possible extension to the apex is visualized by 4 chamber view (Figure 2, right panel). Classical LV hypertrophy cut-off suggestive of HCM in the general adult population is $15 \mathrm{~mm}$ [15]. Usually the pattern of LV hypertrophy is asymmetrical, with the anterior septum involved in the majority of cases being also the site of the maximal LV hypertrophy in most patients (Figure 3). In almost $40 \%$ of patients, LV hypertrophy involves two segments, whereas the concentric pattern or hypertrophy confined to the apex are particularly uncommon in Western countries (1\% each) [16]. Recently, it has been demonstrated [17] that mutations in the alpha-cardiac actin gene can express apical HCM or LV non compaction or septal defects. Nevertheless, LV non compaction has to be differentiated from the apical form of HCM (Figure 4).

The heterogeneous distribution of hypertrophy in HCM results in a distortion of internal LV shape allowing algorithms, generally used to measure LV mass, not applicable in this disease. As a consequence, several echocardiographic indexes have been developed to measure the distribution and the extent of LV hypertrophy. Wigle et al [18] proposed a points score system which takes into account the degree of septal thickness, starting from a value of $15 \mathrm{~mm}$, and the extension of 


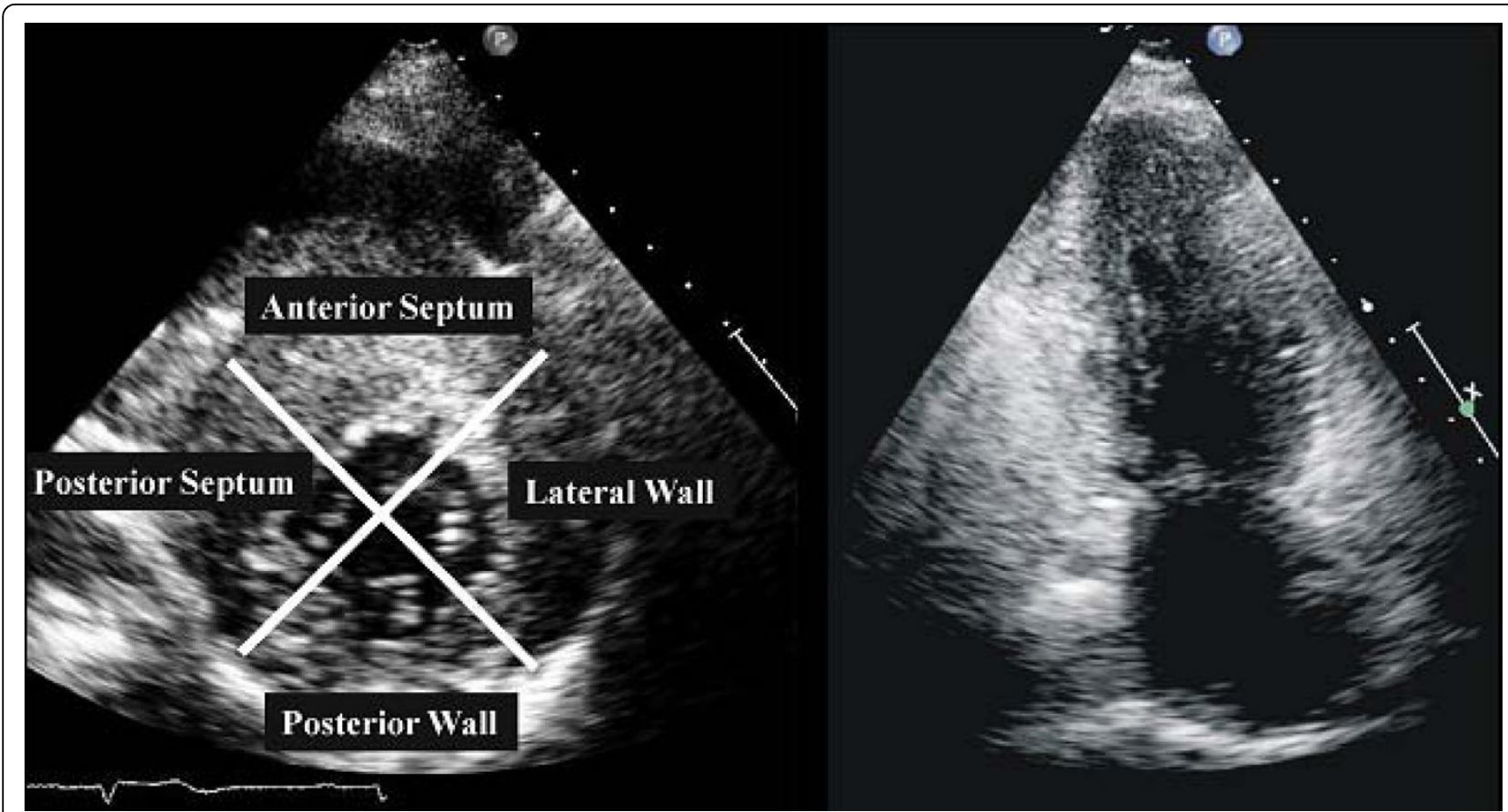

Figure 2 Left ventricular walls dived in four regions in a patients with HCM. Right panel. Apical view in a patient with apical hypertrophy.

hypertrophy up to the point of the apex. In order to calculate this score, the apical 4- chamber view is used to determine the extent of septal involvement, and the parasternal short-axis view at level of the mitral valve leaflet tips to determine the anterolateral wall involvement (Figure 5). Also, Spirito et al [15] have developed a system for assessing the magnitude of hypertrophy using the parasternal long and short-axis views and apical views (Figure 5). The overall extent of hypertrophy is defined as mild if only one LV segment is involved, moderate if two segments are involved and severe if three or more segments are involved [15] (Figure 5). Moreover, an index of hypertrophy, the Spirito-Maron index, is obtained by adding the maximal wall thickness of each LV segments. The most clinical important method is the measurement of the maximal wall thickness (MWT) at any LV level [19] (Figure 5). Extreme wall thickness, i.e. $\geq 30 \mathrm{~mm}$, which can be detected at any site of LV wall, is observed less commonly in older than in younger patients, probably because of sudden death (SD) at a young age and/or of structural remodeling with wall thinning increasing with age. Spirito et al [20] showed that a maximum thickness of $30 \mathrm{~mm}$ or more, present in approximately $10 \%$ of HCM patients, resulted in a substantial long-term risk. However, Elliot et al [21] suggested that extreme hypertrophy is a predictor of SD only when associated with other risk factors such as unexplained syncope, family history of premature SCDs, non-sustained ventricular tachycardia at at Holter-ECG, or an abnormal blood pressure response during exercise. Furthermore, Olivotto et al [22] in a community-based population with HCM reported, during 12-year follow-up, association between maximum LV thickness and SD only in patients diagnosed at a very young age.

The degree of LV hypertrophy varies throughout life. In fact, although the gross phenotypic expression and clinical profile of HCM may occasionally be identified in infants and young children, marked LV hypertrophy is rarely documented during the first years of life [23]. Conversely, rapid changes in LV morphology often occur during adolescence and are frequently delayed completely until the second decade of life, when LV wall thickness may increase rapidly.

Genetic studies among large families demonstrated that morphological LV hypertrophy reaches a plateau at the third decade of life in $\beta$-myosin heavy chain and in $\alpha$-tropomyosin mutations, whereas it increases continuously thought life in cardiac myosin binding protein $\mathrm{C}$ mutations [24]. The clinical implication of such an observation is that, in the contest of family screening, repeat echocardiogram to identify LV hypertrophy at yearly intervals is reasonable during adolescence, whereas repeat imaging is considered for adults at longer time intervals of 5 years. All myocardial segments, and not only the interventricular septum, should be carefully examined for screening purposes. In a recent study where genotyping was the gold standard, 


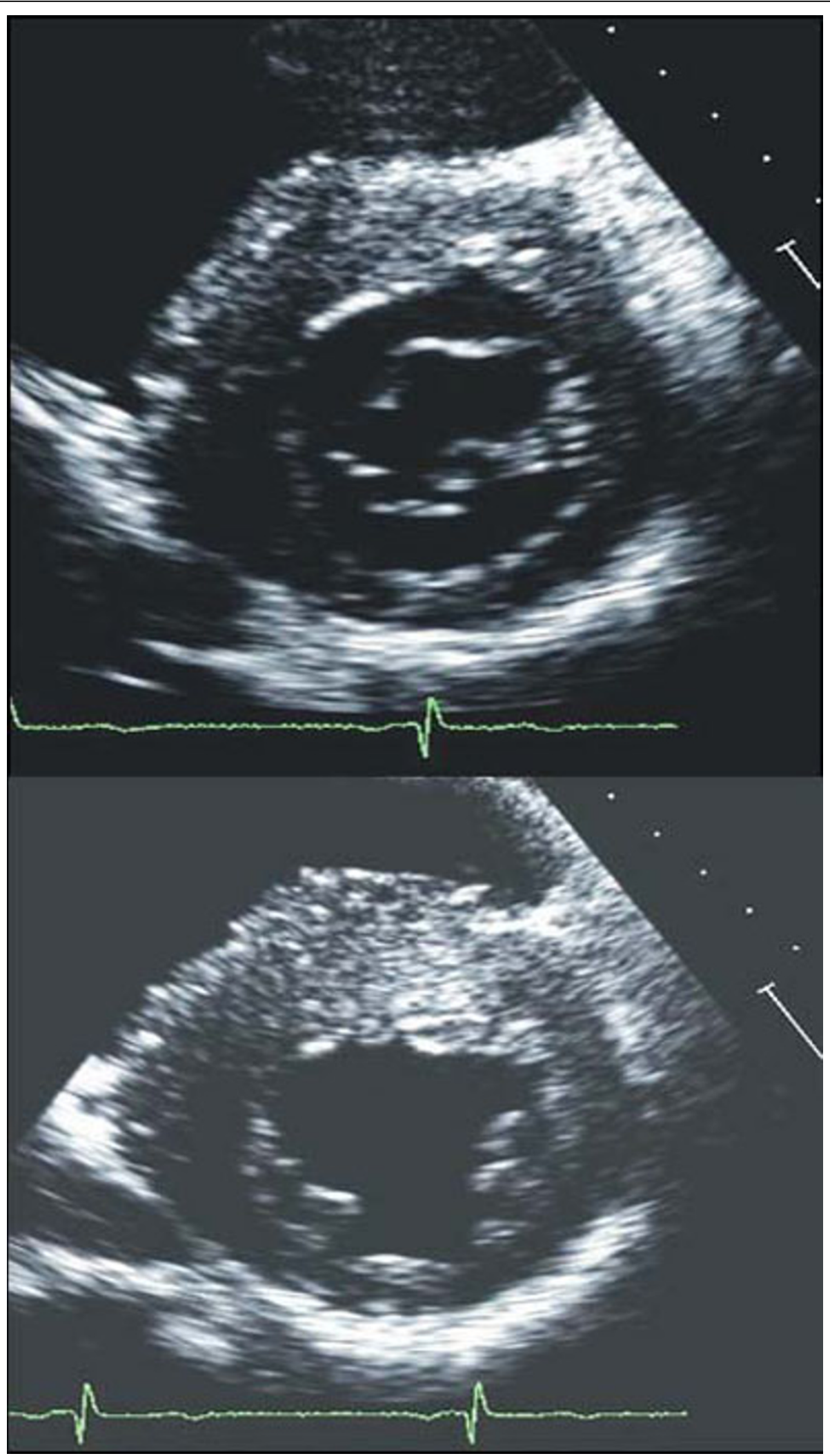

Figure 3 Examples of patients with hypertrophic cardiomyopathy with typical asymmetrical left ventricular hypertrophy. 


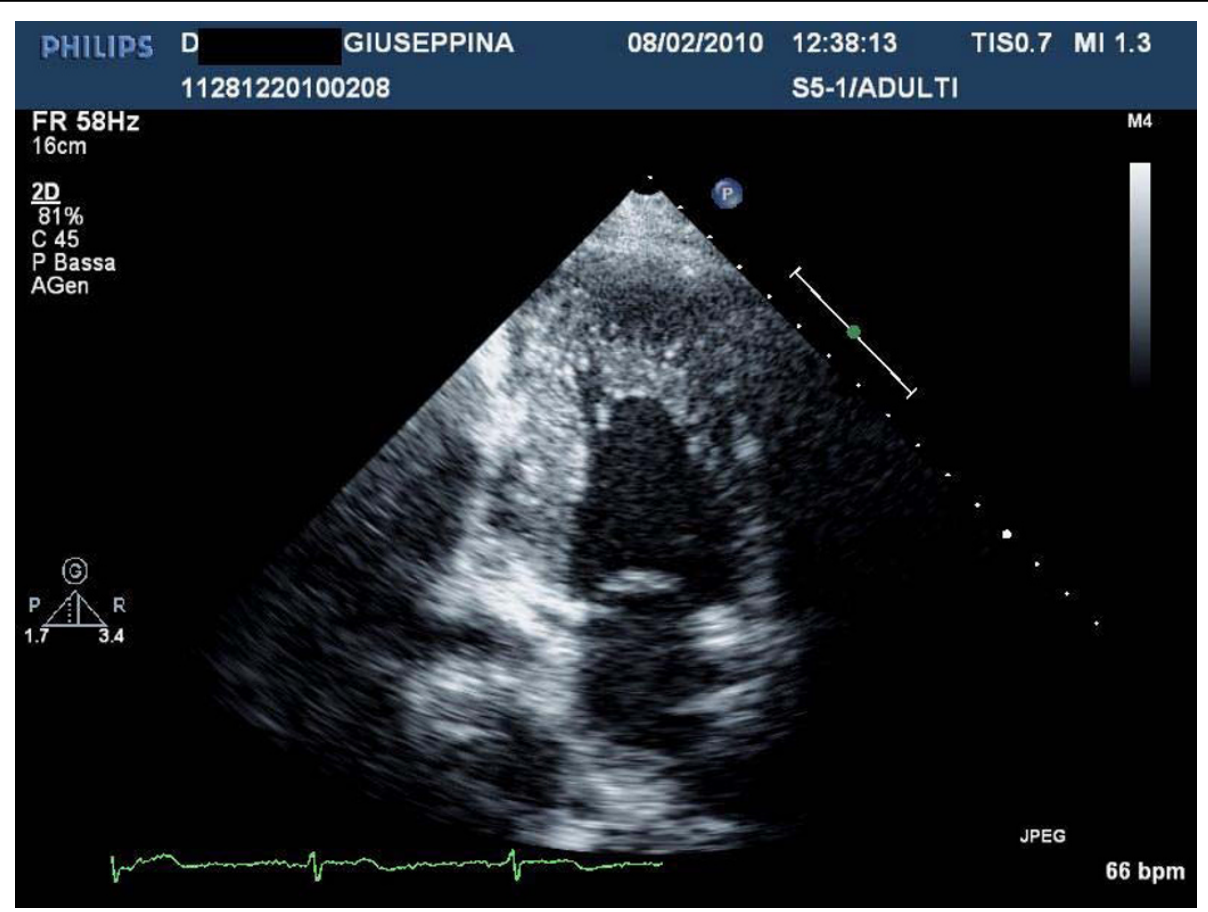

Figure 4 Patient with left ventricular non compaction. This patient was sottoposed to echocardiography in the contest of family screening for apical hypertrophic cardiomyopathy.

the Spirito-Maron hypertrophy score was highly specific with a better sensitivity than MWT [25].

Although LV remodeling in children is characterized by progression of hypertrophy, the changes in cardiac morphology observed in some adults with HCM occur in the context of development of systolic dysfunction (defined as LV ejection fraction $<50 \%$ ) associated or not to LV wall thinning [26] (Figure 6). This unfavorable evolution in the natural history of HCM usually develops during midlife in about $4 \%$ of patients [27]. This phase defined end stage (ES) HCM is a cause of progressive heart failure and is characterized by substantial cardiac remodeling and gradual evolution from the typical hypertrophied, non-dilated, and hyper-dynamic state to one of systolic dysfunction. ES diagnosis is primarily dependent on ejection fraction $<50 \%$, and ES commonly does not present as a dilated cardiomyopathy, with only almost $50 \%$ of patients showing associated LV cavity enlargement or regression in wall thickness; a small proportion of ES patients even demonstrate persistent marked hypertrophy with non-dilated left ventricle [27]. Clinical course is variable but generally unfavorable, and vigilant follow-up are required for timely identification of transition to ES, in order to establish appropriate pharmacological treatment for systolic pump failure, implantable defibrillator for sudden death prevention, heart transplantation.
Cross-sectional echocardiographic analyses of large HCM patient populations encompassing a broad age spectrum $[28,29]$ have documented morphologic differences between youthful and older patients indicating that gradual LV remodeling involving some degree of wall thinning may occur slowly over decades and may be an obligatory pathway in the natural history of HCM [28]

At opposite site, there is evidence of high degree of hypertrophy suggestive of HCM in elderly patients with and without history of arterial hypertension [30,31]. In these patients genetic and family screening are recommended, although technique such as Tissue Doppler Imaging (TDI) and/or strain rate imaging may help in the differential diagnosis as reported below [32].

Finally, among the spectrum of sarcomeric contractile protein disease, idiopathic restrictive cardiomyopathy is part of the clinical expression of cardiac troponin I mutations [33].

\section{LV hypertrophy in other forms of genetic diseases}

Echocardiography can visualize thickened LV walls with high sensibility and specificity, however it cannot distinguish conditions based on myocyte hypertrophy from those in which LV mass and wall thickness are increased by interstitial infiltration or intracellular accumulation of metabolic substrates. Cardiac magnetic resonance (MRI) may help into diagnostic iter 


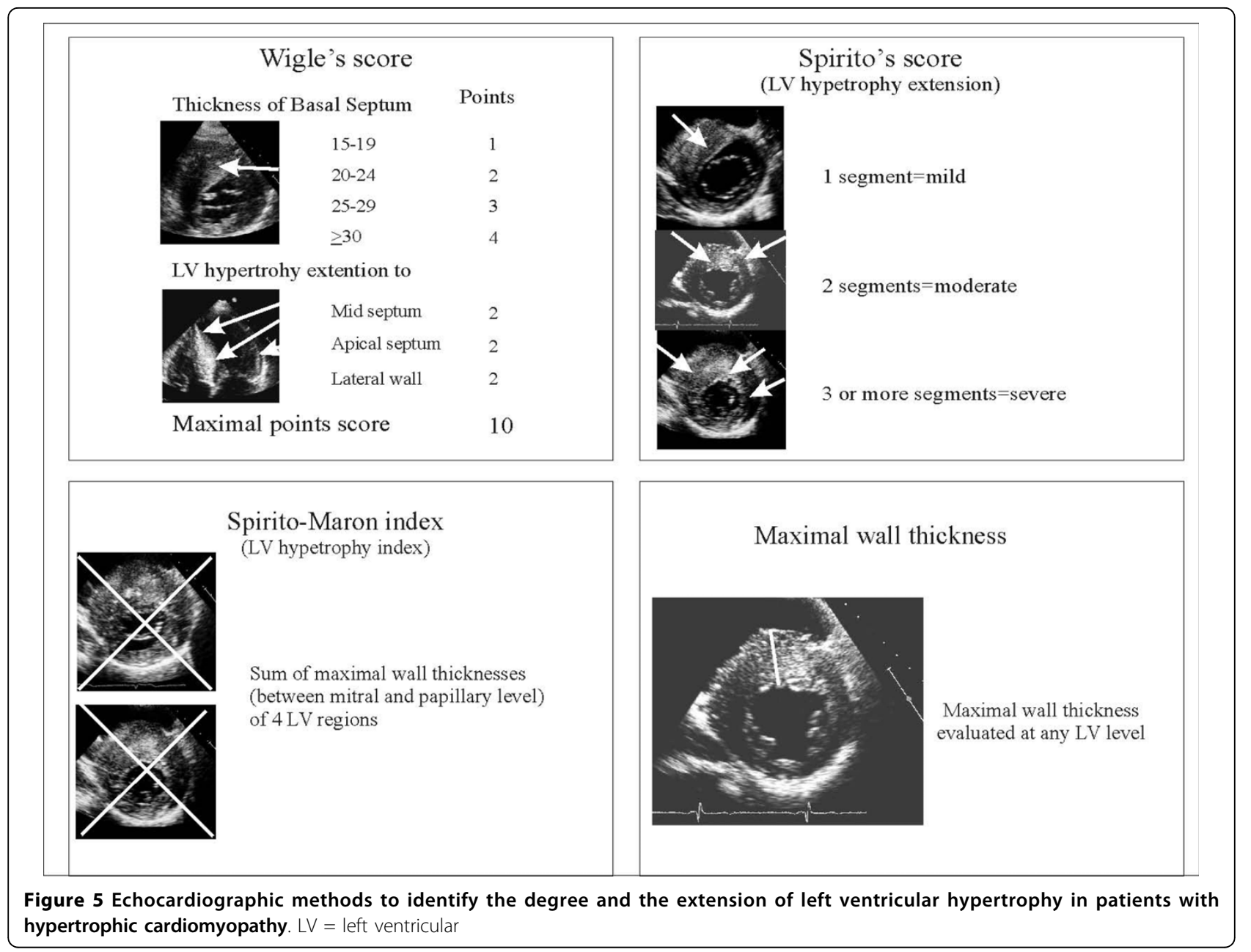

(see below), moreover the final diagnosis is given only in some specific conditions by myocardial biopsy, and in particular is not indicated for the final diagnosis of HCM $[34,35]$. On the other hands, it is not reasonable to investigate for each entity capable of induce increased wall thickness because of anamnestic, clinical and instrumental data that serve to orient the diagnosis before the echocardiographic study.

In the contest of genetic disease, thickening of LV walls can results also by mutations in non sarcomeric proteins involving or the gene encoding the $\gamma$-2-regulatory subunit of the AMP-activated protein kinase (PRKAG2), or the gene encoding lysosome-associated membrane protein 2 (LAMP-2), resulting in Danon-type storage disease with clinical manifestations limited largely to the heart (usually with massive degrees of LV hypertrophy and ventricular pre-excitation) [9] (Figure 7). Overall these condition are X-linked, and, thus, important clinical clues are male gender and young age.

Anderson-Fabry disease is a relatively frequent cause of idiopathic LV hypertrophy. It is a X-linked lysosomal storage disorder caused by $\alpha$-galactosidase mutations and it is characterized clinically by widespread variety of signs and symptoms. Cardiac findings include LV hypertrophy, showing a symmetrical pattern in the majority of cases, mild diastolic dysfunction and preserved LV ejection fraction as well as no LV outflow tract obstruction (LVOTG) (Figure 8). The use of a binary appearance at echocardiography of LV endocardial border has been questioned in that is not a sensitive marker and it can not be routinely used to differentiate Anderson-Fabry disease from HCM $[7,8]$. Symptomatic cardiac involvement usually occurs in most affected males, whereas female carriers present with minimal or no symptoms. Retrospective studies found a prevalence of Anderson-Fabry disease in 4-6\% of patients previously classified as HCM, suggesting that the disease should be suspected in male patients with concentric LV hypertrophy and no family history of HCM or with inheritance consistent with X-linked disease [36].

Mitochondrial disorders result from abnormalities in mitochondrial DNA and function; mitochondrial DNA is inherited maternally, and most of these disorders are 


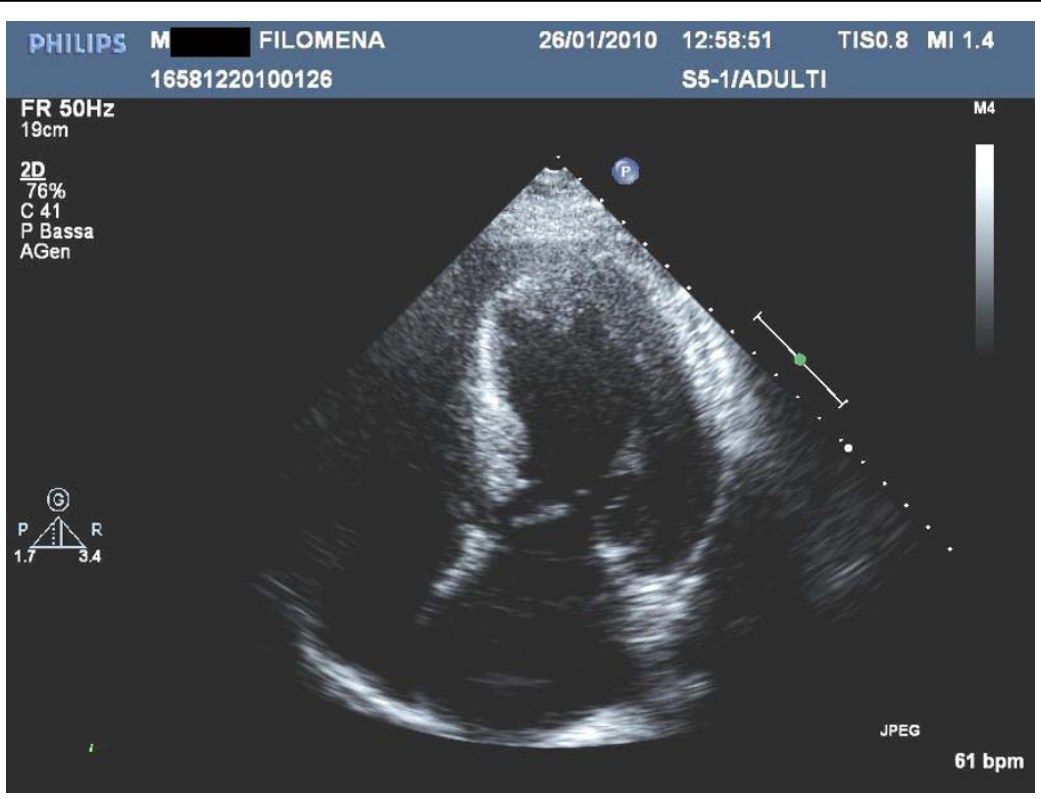

Figure 6 Patient with end stage hypertrophic cardiomyopathy: note the absence of thinning: the left ventricular ejection fraction is $40 \%$.

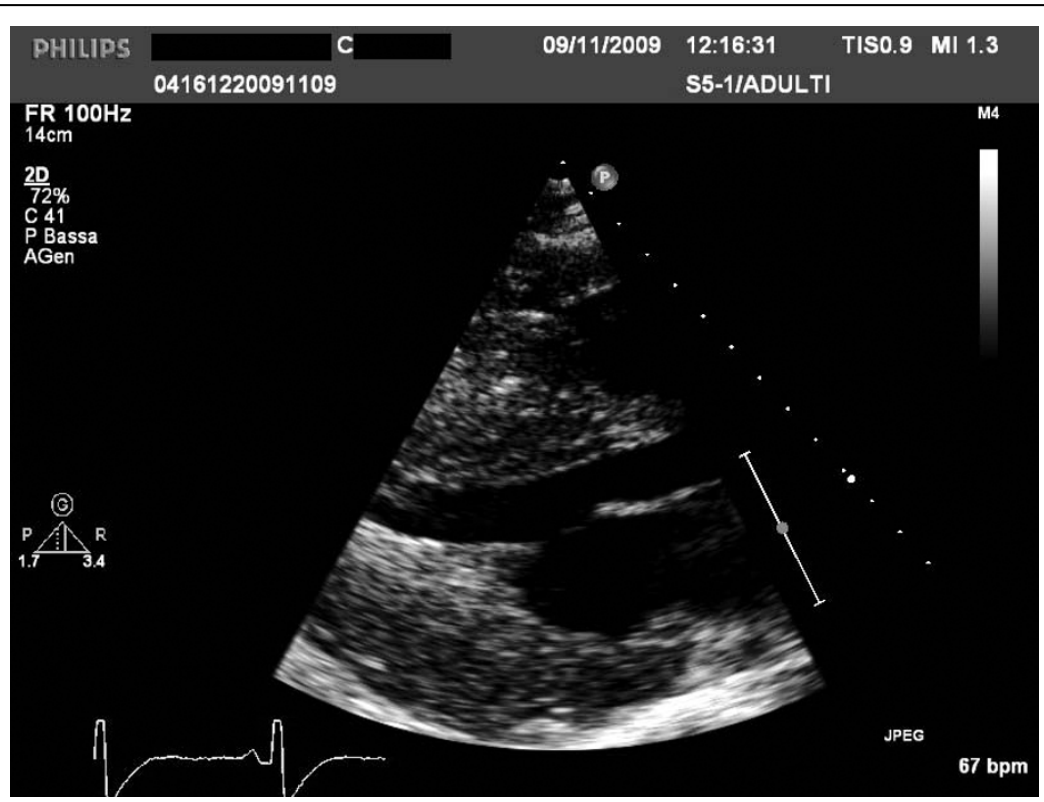

Figure 7 Patient with extreme left ventricular symmetrical hypertrophy. At electrocardiography patient showed a short PR. The patient was referred for aminotransferase and creatinine phosphokinase dosage and for genetic testing.

transmitted from mother to children of both sexes. In some mitochondrial disorders, LV concentric hypertrophy is present as well dilated cardiomyopathy, which probably represents a progression from the hypertrophic form. In most patients, conduction abnormalities are present [37] (Figure 9).

Involvement of the heart is a common finding and is the most frequent cause of death in amyloidosis; cardiac amyloidosis occurs more commonly in men than in women, and it is rare before the age of 40 years. The onset of clinical cardiac disease usually occurs late in life. Echocardiography is characterized in the majority of cases by symmetric LV hypertrophy, dilated atria and pericardial effusion (Figure 10). In some case the degree and the distribution of hypertrophy may resemble HCM, however LV hypertrophy together with the 


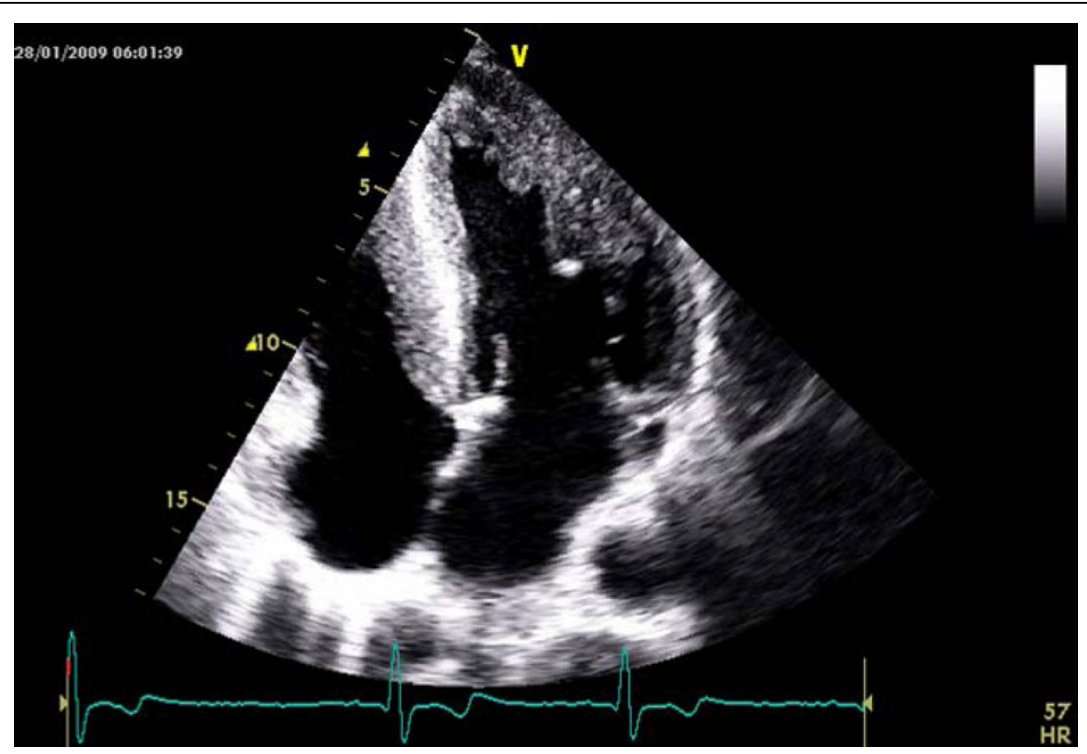

Figure 8 Young male with definitive diagnosis of Anderson- Fabry disease. For courtesy of Dr L. Spinelli.

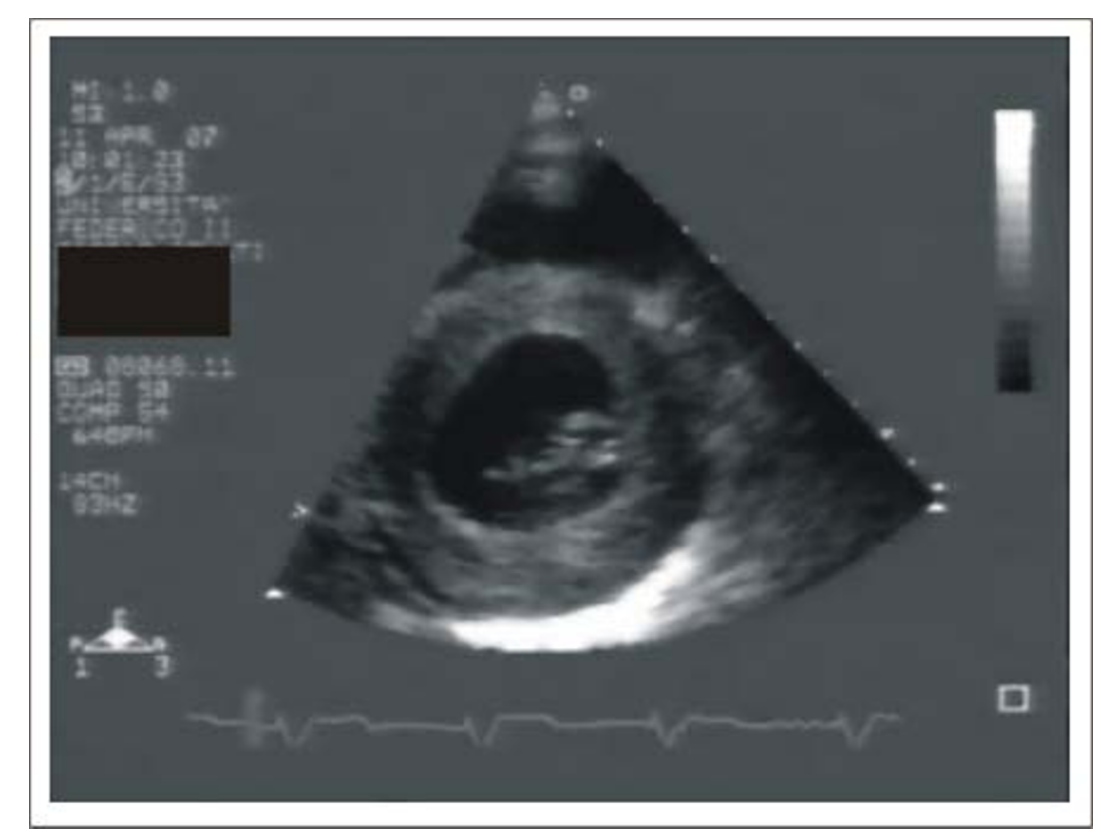

Figure 9 Patient with definite diagnosis of mithocondropathy done by neurologists. Echocardiography shows mild symmetric hypertrophy with mild reduction of left ventricular ejection fraction. During follow-up patient developed severe grade of AV block needing pace-maker and severe reduction of ejection fraction needing resynchronization.

evidence of low voltage at electrocardiogram help in the differential diagnosis with pericardial effusion and with HCM [38].

\section{Athletic heart and HCM}

One of the most discussed issue is how to role out HCM in athletes. Diagnosis of HCM in athletes is important, given the high propensity to sudden cardiac death in
HCM patients engaging in competitive sports as well as other physically intense activity [39]. Although in Italy the ECG, which is routinely performed in competitive athletes, has dramatically reduced the incidence of sudden death due to the identification of diseases such as HCM [40], sometimes the diagnosis can be still particularly challenging in athletes with an advanced degree of physiologic LV hypertrophy. Cardiac hypertrophic 


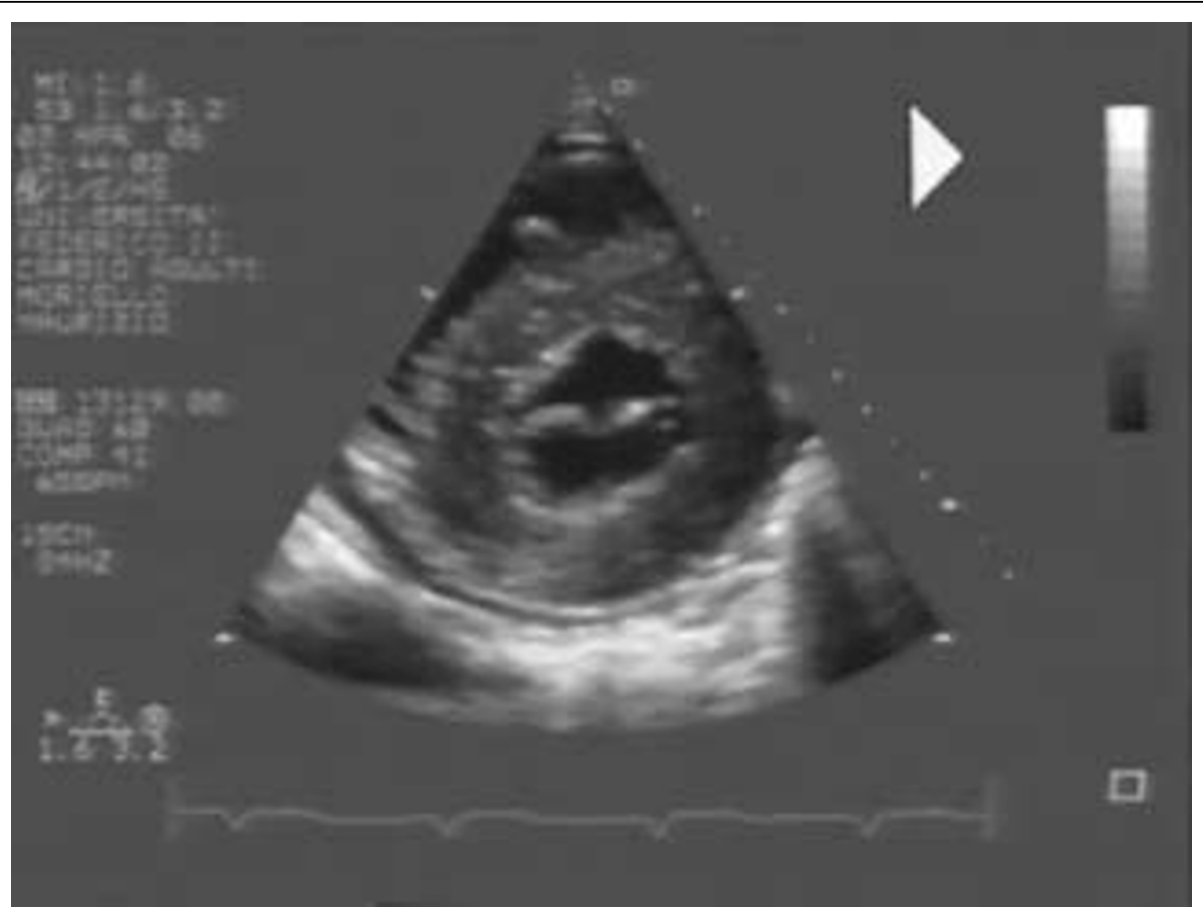

Figure 10 Patient with definitive diagnosis of amyloidosis. Note the pericardial effusion.

response to training is different between sports [41], between individuals of the same race undergoing the same training [42], and is different between races [43]; thus, there is a very huge variability in LV hypertrophy in athletes, which sometimes is suggestive of HCM. Helpful clues include the presence of wall thickness $>12 \mathrm{~mm}$ in the presence of a non-dilated LV in HCM, because HCM patients usually have normal or reduced LV dimensions and no cavity dilatation ( $>55 \mathrm{~mm}$ is common in athletes), except with disease progression and systolic dysfunction. HCM patients have abnormal myocardial function as detected by TDI, including mitral annulus velocities or strain rate [44]. In equivocal cases, it is reasonable to recommend stopping exercise with repeat imaging later, when one would expect regression of physiologic but not pathologic LV hypertrophy $[44,45]$.

In Figure 11 we suggest a clinical and echocardiographic method to approach patients with unexplained LV hypertrophy.

\section{Right ventricular hypertrophy}

Right ventricular hypertrophy is diagnosed when two or more right ventricular segments are hypertrophied and when at least two right ventricular wall measurements exceed two standard deviations from the mean recorded in normal subjects. Using these criterions McKenna et al [46] reported right ventricular hypertrophy in $44 \%$ of 73 patients with HCM. More recently, Maron at al found [47] in $46 \mathrm{HCM}$ patients studied by cardiac MRI, that right ventricular mass was increased in the majority of them. To date, the clinical and prognostic significance of right ventricular hypertrophy is not known.

\section{LVOTG}

Although SAM is the most frequent mechanism of LVOTG, obstruction can occur at mid-ventricular level or at multiple levels in the same patient and is variable with time. Continuous Doppler will give informations about the degree of obstruction (see later) whereas by pulse wave Doppler LV mapping will be performed to determine the site of obstruction. Mid-ventricular obstruction has been diagnosed by the typical angiographic feature of hourglass appearance of the left ventricle with mid-ventricular obliteration and apical chamber that is variable in size and contractility. Echocardiography has the same potential to identify this haemodynamic type of HCM (Figure 12). Patients with mid-ventricular obstruction are at high risk to develop segmental, like apical aneurysm, or diffuse LV wall motion abnormalities [48]. Moreover, structural abnormalities of the mitral valve, such as increased mitral valve area and abnormal direct insertion of papillary muscles into anterior mitral leaflet (Figure 13) can be detected by echocardiography orienting treatments' strategies.

\section{LA volume}

LA volume measured by two-dimensional echocardiography has some clinical and prognostic implications. 


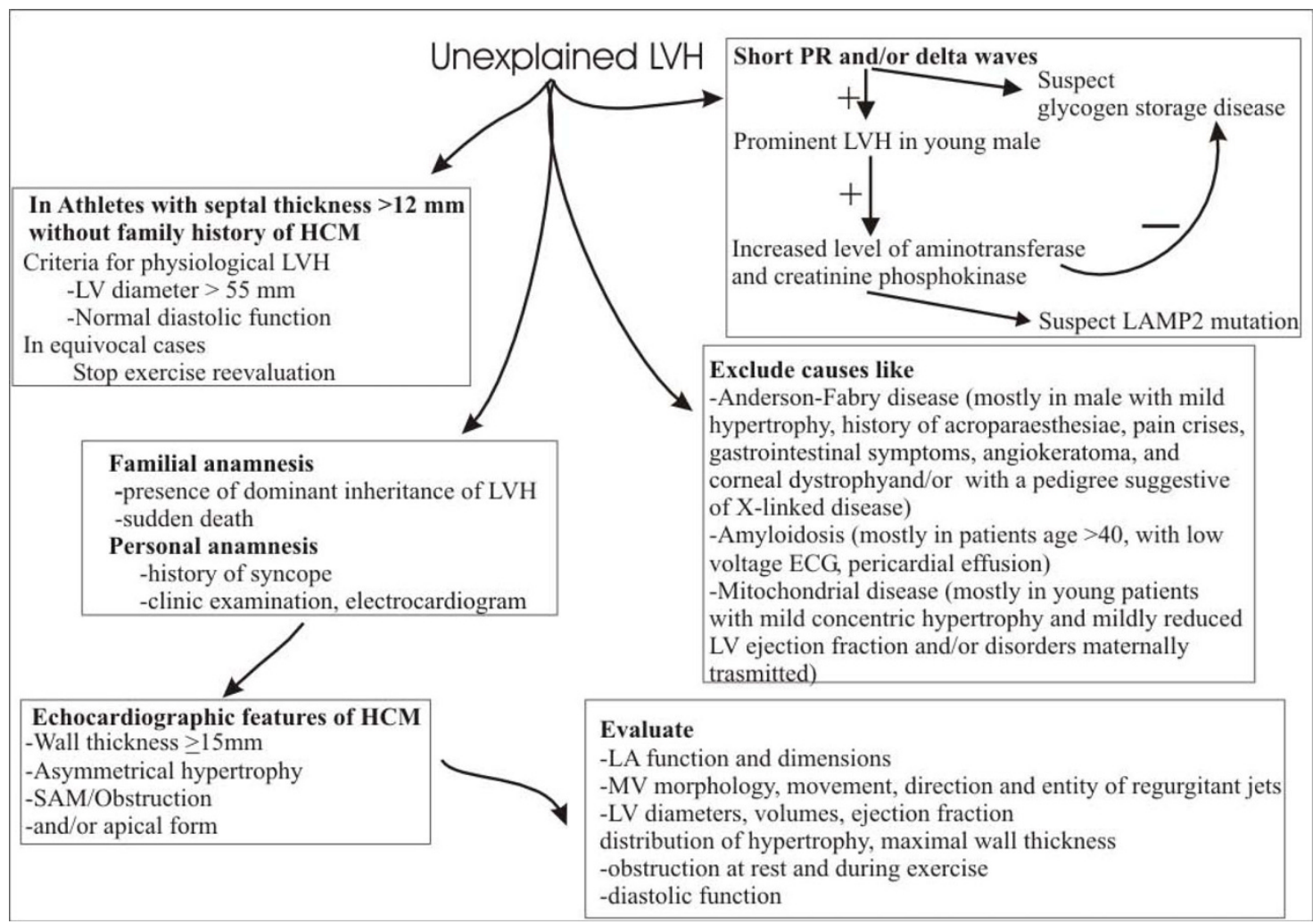

Figure 11 Scheme for the clinical and echocardiographic approach in patients with unexplained left ventricular hypertrophy. LV = left ventricular

LA remodeling, measured by LA volume, relates directly with exercise tolerance as demonstrated by Sachdev et al [49] in patients without LVOTG either at rest and during provocation, suggesting that this parameter may serve as a surrogate marker of chronic diastolic burden. Moreover, patients with normal LA volume which show dilatation during follow-up, i.e. $>3 \mathrm{ml} /$ year, have a worse outcome than patients with normal and stable LA volume during follow-up and similar to that of patients with LA dilation at baseline [50].

\section{Doppler echocardiography}

Each Doppler technique offers relevant contribution in the analysis of patients with HCM .

\section{Color Doppler echocardiography}

Evaluation of the presence and degree of mitral regurgitation is performed by color Doppler echocardiography. Mitral regurgitation occurs in almost all patients with obstructive HCM as a consequence of SAM which induces abnormal mitral leaflet coaptation and may be an important cause of dyspnea. When additional mitral valve abnormalities other than SAM are not observed, a direct relation between the pressure gradient and the severity of MR is evident [51]. The direction of the mitral regurgitation jet is useful in identifying patients with independent mitral disease. In fact SAM induces a mitral regurgitation jet directed posteriorly, whereas in presence of a intrinsic mitral valve disease due to annular, papillary or leaflet disease, patients with obstruction and mitral regurgitation can show a systolic mitral anterior directed jet [51].

\section{Continuous Doppler echocardiography. Exercise echocardiography}

Approximately $25 \%$ of patients with HCM have a significant resting pressure gradient, i.e. $\geq 30 \mathrm{mmHg}$, between the body and LV outflow tract. This is nearly always accompanied by SAM. Continuous wave Doppler is used to determine peak LVOTG with caution exercised to exclude the mitral regurgitation jet [52] (Figure 14). This latter differentiation may be difficult especially in patients with mitral regurgitation jet directed anteriorly. In these cases it is of help the M-mode echocardiographic evaluation of SAM.

It is well recognized that some patients without outflow obstruction at rest have gradients that can be provoked by physiological and pharmacological interventions that diminish LV end-diastolic volume or augment LV contractility. The term labile obstruction has been used to describe the spontaneous appearance and disappearance of obstruction and latent obstruction 


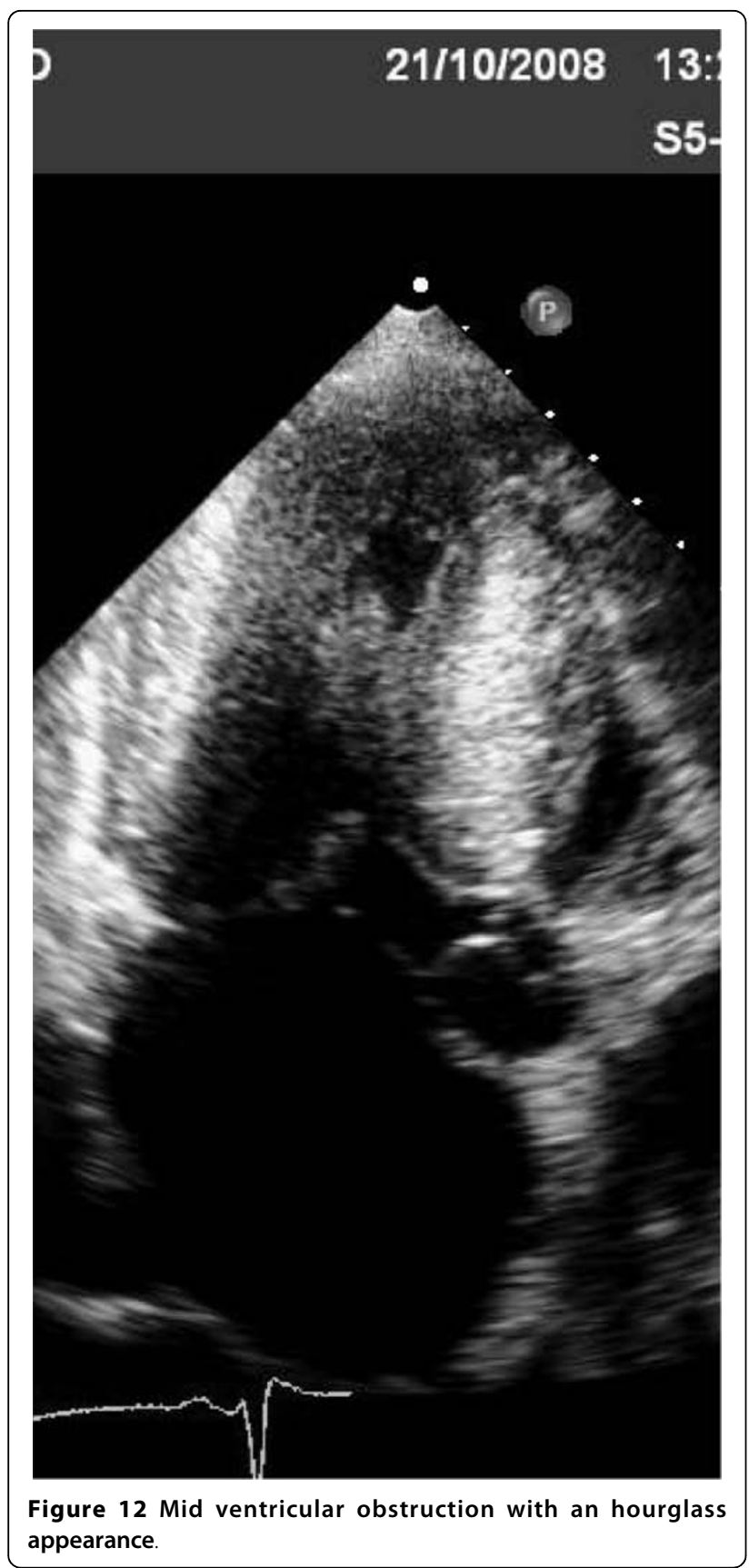

to describe gradients that only appear with provocation. A number of methods can provoke obstruction in the echocardiography laboratory, including Valsalva maneuver, amyl nitrite, and dobutamine. However, these methods are not standardized and can underestimate the degree of obstruction such as Valsalva maneuver or have low specificity such as dobutamine. Exercise is a physiologic means of provoking latent LVOTG. Over $50 \%$ of HCM patients without significant outflow tract obstruction at rest will demonstrate outflow gradients over $30 \mathrm{mmHg}$ with exercise $[53,54]$. Although supine bike exercise is more conducive to acquiring multiple haemodynamic data sets, this position increases venous return and might decrease the likelihood and extent of LVOTG. Accordingly, upright exercise, which has the greatest resemblance to daily physiologic activities, should be used.

Right ventricular outflow tract obstruction may coexist with LVOTG in a minority of patients with massive septal hypertrophy and occasionally it is isolated [55].

Figure 15 shows the echo findings which are strong predictors of prognosis in patients with HCM.

\section{Pulsed Doppler}

Pulsed Doppler at mitral and pulmonary level is used to assess the presence and the degree of diastolic dysfunction. Almost all patients with HCM have some degree of LV diastolic dysfunction. Figure 16 reports a scheme of the molecular, morphological and haemodynamic factors which may contribute to diastolic dysfunction in HCM. These complex mechanisms determine that all phases of diastole are altered. Isovolumic relaxation is slowed and prolonged, the rate of rapid filling is diminished, atrial contribution to filling is increased as well as LV chamber stiffness [56]. The importance of diastolic dysfunction in HCM has led to an extensive search for accurate, noninvasive methods of quantifying its severity. When LV enddiastolic pressure is considered, the echo pulsed Doppler parameter with a good relationship is represented by the difference in duration between the atrial contraction wave at mitral and pulmonary level [57]. Lombardi et al [58] demonstrated that as the difference in duration worsens myocardial collagen synthesis prevails over degradation; moreover, an echocardiography index of myocardial fibrosis, i.e. diastolic back scatter, increases [59], suggesting a strong interplay between diastolic function and myocardial fibrosis.

\section{New echocardiographic technologies}

New technologies have been employed in the pathophysiological assessment, in preclinical diagnosis, in differential diagnosis, and in risk stratification of HCM.

\section{Contrast echocardiography}

Contrast echocardiography currently is used to enhance endocardial definition, Doppler signals, and to evaluate myocardial perfusion during percutaneous transluminal septal myocardial ablation (PTSMA). PTSMA is a catheter interventional treatment which involves the introduction of absolute alcohol into a septal perforator branch of the left anterior descending coronary artery to produce a myocardial infarction within the proximal ventricular septum. The aim is similar to that of myotomy-myectomy, i.e. reducing the basal septal thickness and excursion enlarging the LV outflow tract and, thereby, lessening the SAM of the mitral valve and 


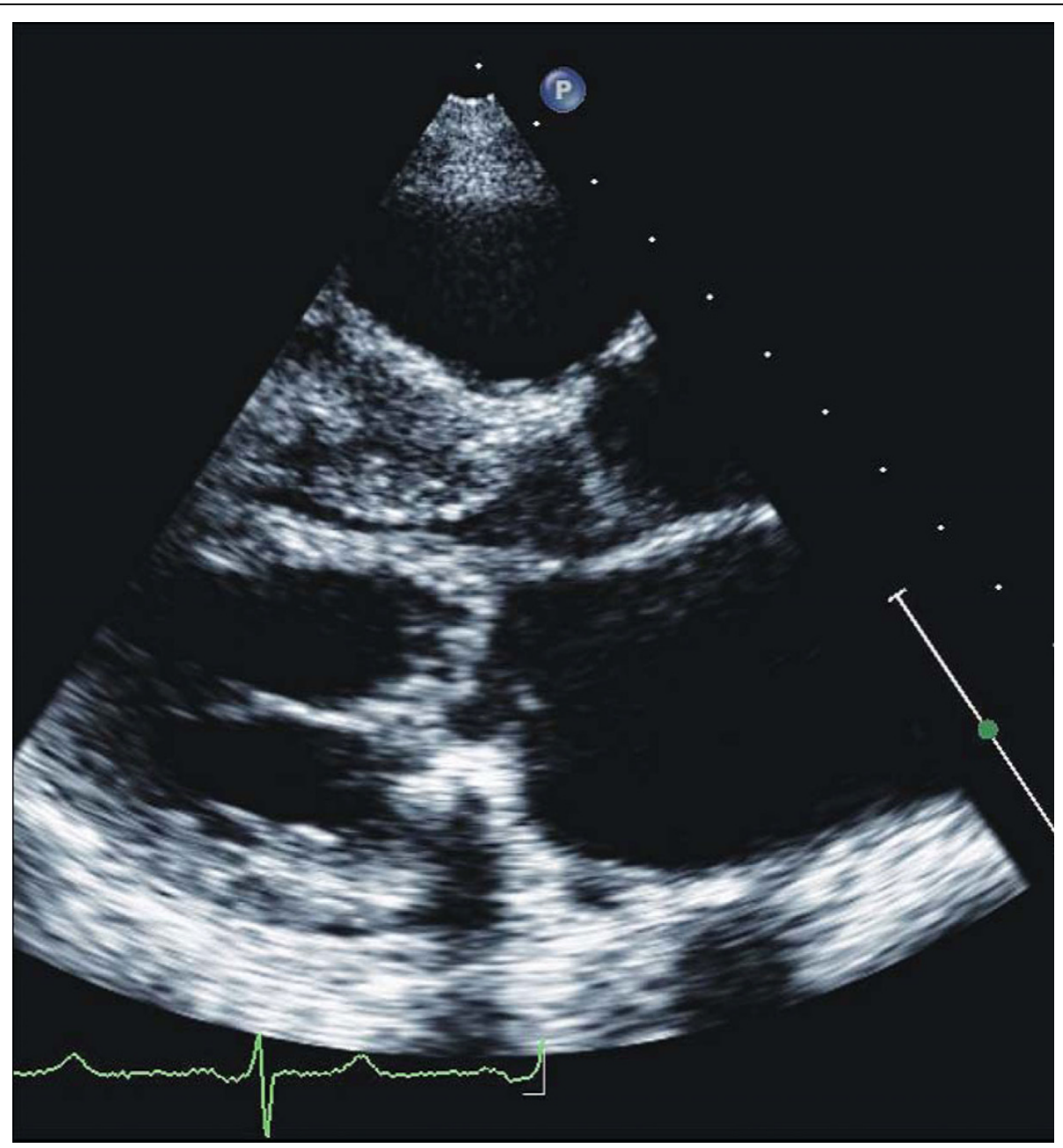

Figure 13 Example of patients with abnormal direct insertion of papillary muscles into anterior mitral leaflet.

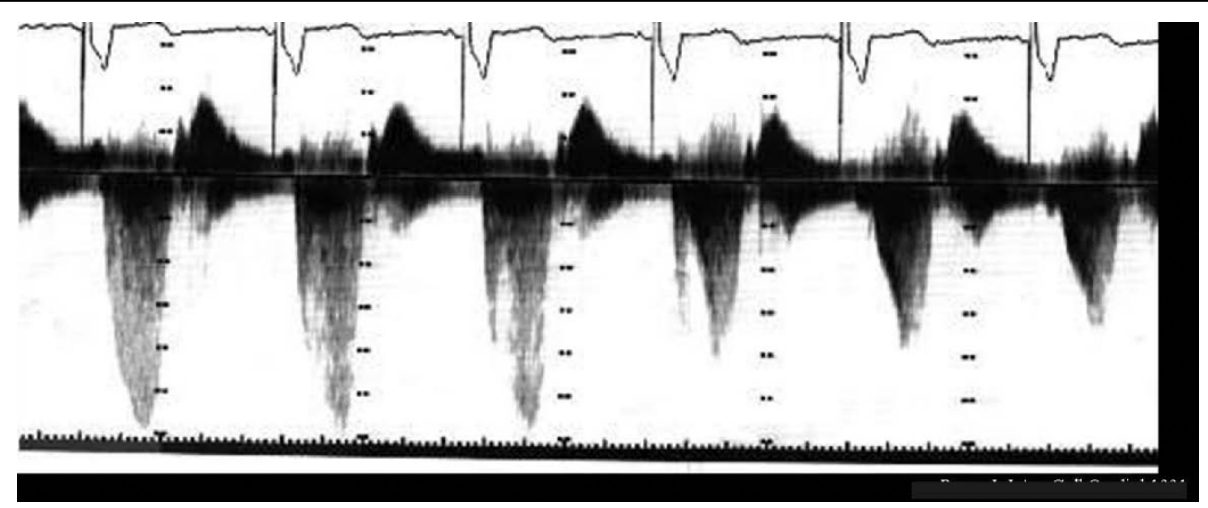

Figure 14 Differentiation between mitral regurgitation (first cardiac cycles) and left ventricular outflow tract gradient (last cardiac cycles). This was obtained by orienting the probe more medially and anteriorly. 


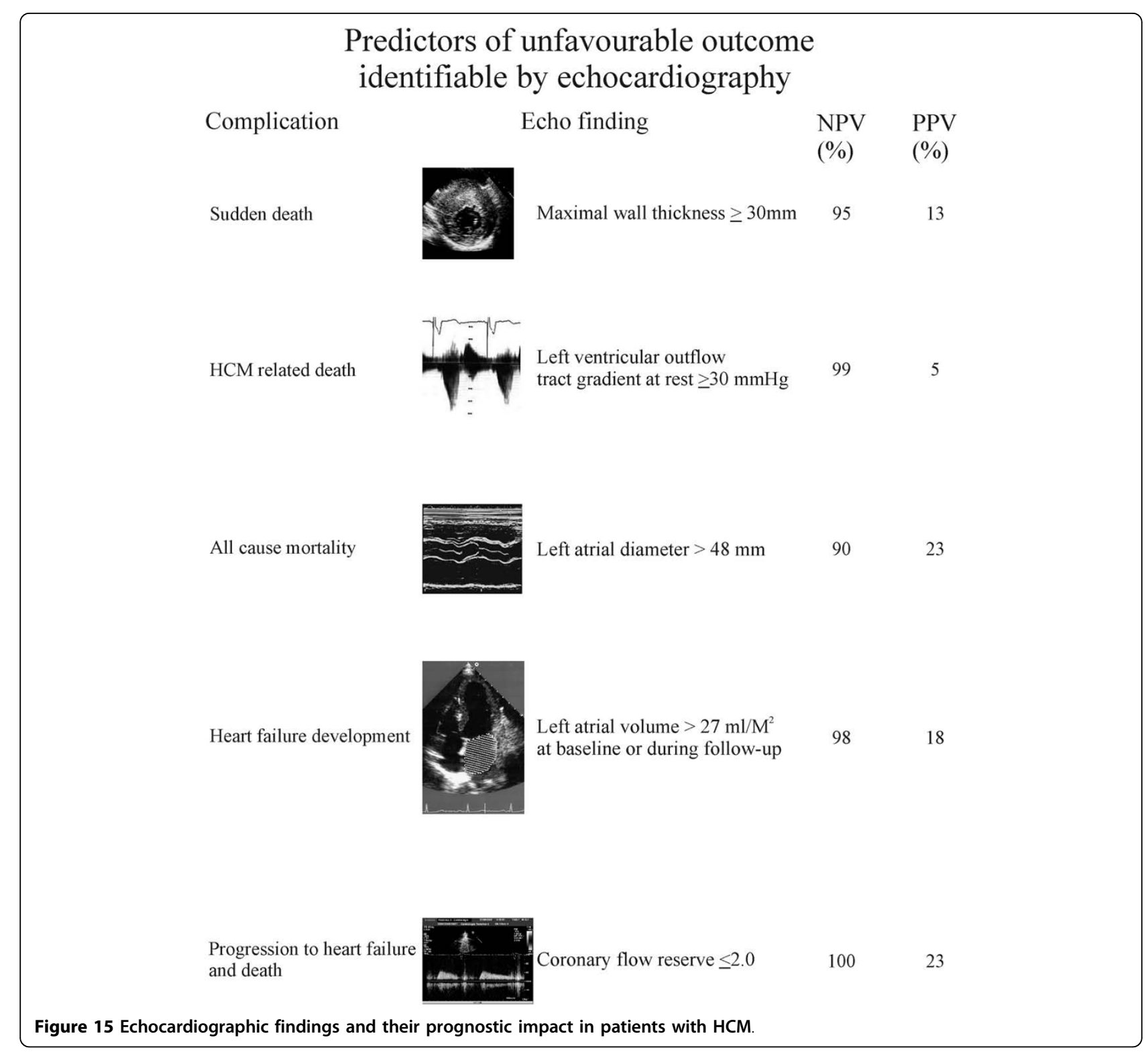

mitral regurgitation. The introduction of the echo contrast has proved to reduced the side effects of the technique: it selects the appropriate septal perforator branch determining the precise area of septum targeted for alcohol ablation and evaluates whether selected septal perforator also perfuses other distant and unwanted areas of LV or right ventricular myocardium or papillary muscles [60].

A potential role for contrast enhancement in the diagnosis of apical HCM has been demonstrated [61], although systematic studies have not be yet performed.

\section{Tissue Doppler Imaging}

Given the complex interplay of factors causing diastolic dysfunction in HCM, it should not be surprising that no single non-invasive measure has been definitively validated. Nagueh et al [57] suggested that the ratio of early transmitral (E) to tissue Doppler early diastolic (e') velocities of the lateral mitral annulus accurately quantified LV pressures, in particular the LV pressure before atrial contraction, an E/e' $\geq 10$ showed the best sensitivity and specificity for identifying LV pre-A pressure $>15 \mathrm{mmHg}$. However, that ratio shows only a modest correlation when related to mean left atrial (LA) pressure, and, moreover, the predictive accuracy of the E/e' ratio for estimation of mean LA pressure in an individual patient was modest [62]. However, in some study this parameter identifies patients with low exercise capacity $[63,64]$. 


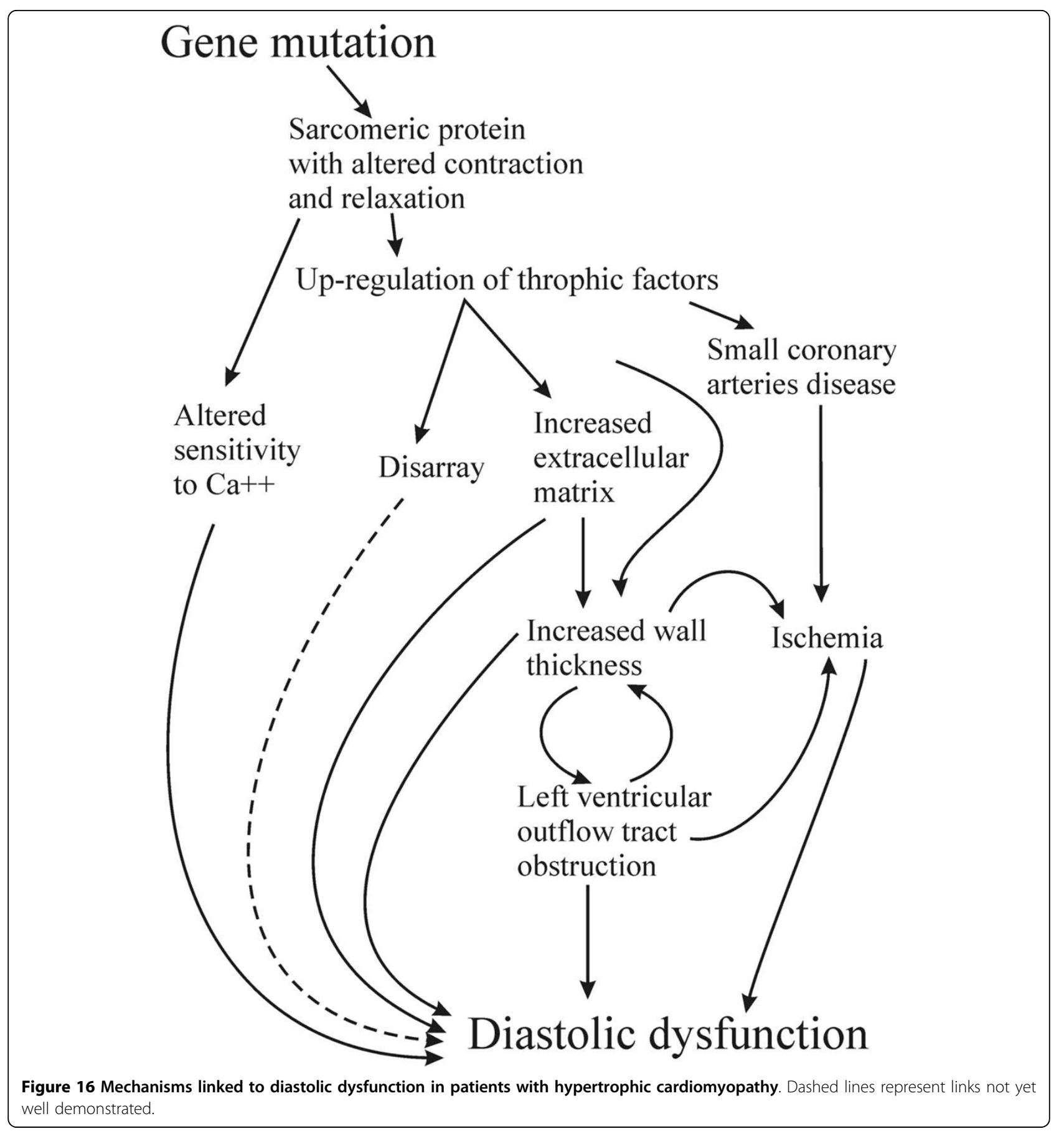

TDI has been investigated in the preclinical diagnosis of HCM. Studies from transgenic animal models revealed some abnormal myocardial function at a time preceding the development of LV hypertrophy, firstly due to alterations in $\mathrm{Ca}^{++}$sensitivity [65] which probably induce low TDI velocities at annular mitral level. Although some reports have provided encouraging results $[66,67]$, additional data from a larger number of subjects are needed to determine TDI velocity values that provide the highest diagnostic accuracy.

\section{Strain rate imaging}

Patients with HCM may show regional differences in wall motion at rest [45]. Betocchi et al [68] demonstrated that LV regions with less pronounced myopathic process are those with normal stiffness and with supernormal wall motion. In contrast, the stiffer septum 
shows reduced wall motion compared with adjacent regions. Other mechanisms may explain regional asynergy such as anatomic nonuniformity, altered calcium handling, subendocardial ischemia and altered glucose metabolism.

In the last decade several papers have been published using strain rate technique, either TDI and speckle (2D gray-scale method), to investigate regional systolic function. Ganame et al [69] demonstrated in a pediatric population with HCM that, despite normal global systolic function, longitudinal and radial systolic myocardial deformation were heterogeneously reduced and the alteration was more pronounced in the more severely hypertrophied myocardial segments. There are discrepancies between measures of regional and global myocardial functions for several reasons. Endocardial indexes of LV function such as fractional shortening and ejection fraction are known to overestimate systolic function in the presence of LV hypertrophy. Moreover, patients with HCM have a smaller end-diastolic diameter and increased wall thickness, resulting in a decreased ventricular afterload which, in presence of significant hypertrophy, will result in higher values of fractional shortening and ejection fraction, despite reduced wall thickening. When regional systolic function was studied by strain rate imaging, there was a direct relationship between systolic deformation and exercise capacity in a pediatric population with HCM, suggesting that systolic function, even when ejection fraction is normal or supernormal, has a role into determination of clinical status in these selected group of patients. In another study, a regional double peak systolic sign indicating a second systolic peak during systole, had strong relationship with the late enhancement at nuclear magnetic resonance, suggesting the possibility to diagnose regional myocardial fibrosis by echocardiography [70] (Figure 17).

Strain rate imaging has been shown to measure accurately LV torsion [71]. LV untwisting is linked temporally with early diastolic base-to-apex pressure gradients, enhanced by exercise, which may assist efficient LV filling. This effect appears blunted during exercise in HCM [72], particularly in patients with the obstructive form [73].

A frequent clinical issue is to establish the final diagnosis in patients with high degree of LV hypertrophy and arterial hypertension; recently, more severely reduced systolic compression (by strain Doppler echocardiography) along with asymmetric LV hypertrophy readily identified HCM patients from those with hypertension [32]. Receiver-operator characteristic curve analysis identified the optimal cut-off value of strain, i.e. systolic longitudinal strain by 4 and 2 chamber views, for discrimination between HCM and hypertensive LV hypertrophy, as $-10.6 \%$; this value was associated with a sensitivity, specificity, and predictive accuracy of 85,100 , and $91.2 \%$, respectively. Similarly, an intraventricular septal/posterior wall thicknesses ratio of 1.3 was associated with a sensitivity of $65 \%$, specificity of $100 \%$, and predictive accuracy of $79.4 \%$. A discriminant function test revealed that a discriminant score $(Z)$ defined by the following equation yielded the highest discriminant probability of $96.1 \%: \mathrm{Z}=-1.7044+(15.2316 \times \mathrm{IVST} /$ $\mathrm{PWT})+(1.52687 \times$ strain $)$, where $\mathrm{Z}>0$ indicates a diagnosis of HCM and $Z<0$ indicates a diagnosis of hypertensive LV hypertrophy.

Strain rate imaging has been involved in the differentiation of HCM from cardiac amyloidosis in one study where, however, patients with amyloidosis were in the late stage characterized by low ejection fraction. This suggests that the early differentiation of amyloidosis versus HCM using strain (i.e., before the development of systolic dysfunction) may be still difficult [74].

\section{Real time 3-dimensional echocardiography}

Real time 3-dimensional echocardiography has been applied to determine LV mass, but there is a paucity of data about its accuracy in HCM. To date, MWT remains the best and the more simple and important measurement that should be reported, because it can predict sudden cardiac death in this population.

\section{Coronary flow reserve}

Stress echocardiography with dypiridamole has been used to test prognostic role of electrographic signs of inducible ischemia in patients with HCM. In one paper [75], ECG signs of myocardial ischemia elicited by dipyridamole were frequent identify patients at higher risk of cardiac major and minor events, suggesting a important pathogenetic role of inducible myocardial ischemia in determining adverse cardiac events in these patients.

Quantitative evaluation of coronary flow reserve studied by positron emission tomography is a strong predictor of progression to severe symptoms and to ES HCM [76]. An estimate of coronary flow reserve can be obtained in the echo-lab by the simple transthoracic Doppler echocardiographic approach of the mid-distal left anterior descending artery and recently its prognostic role has been tested in a population of patients with HCM. Cortigiani et al [77], found that patients with reduced coronary flow reserve $(\leq 2)$ have a worse prognosis than patients with normal values $(>2)$. Clinical events recorded during follow-up were death, nonfatal myocardial infarction (defined by typical symptoms, increased cardiac enzyme, and/or electrocardiographic changes), cardioverter- defibrillator implantation, hospitalization for heart failure or unstable angina, syncope, and paroxysmal or chronic atrial fibrillation. Authors found that this coronary flow reserve was a strong and independent predictor of outcome in HCM patients. 


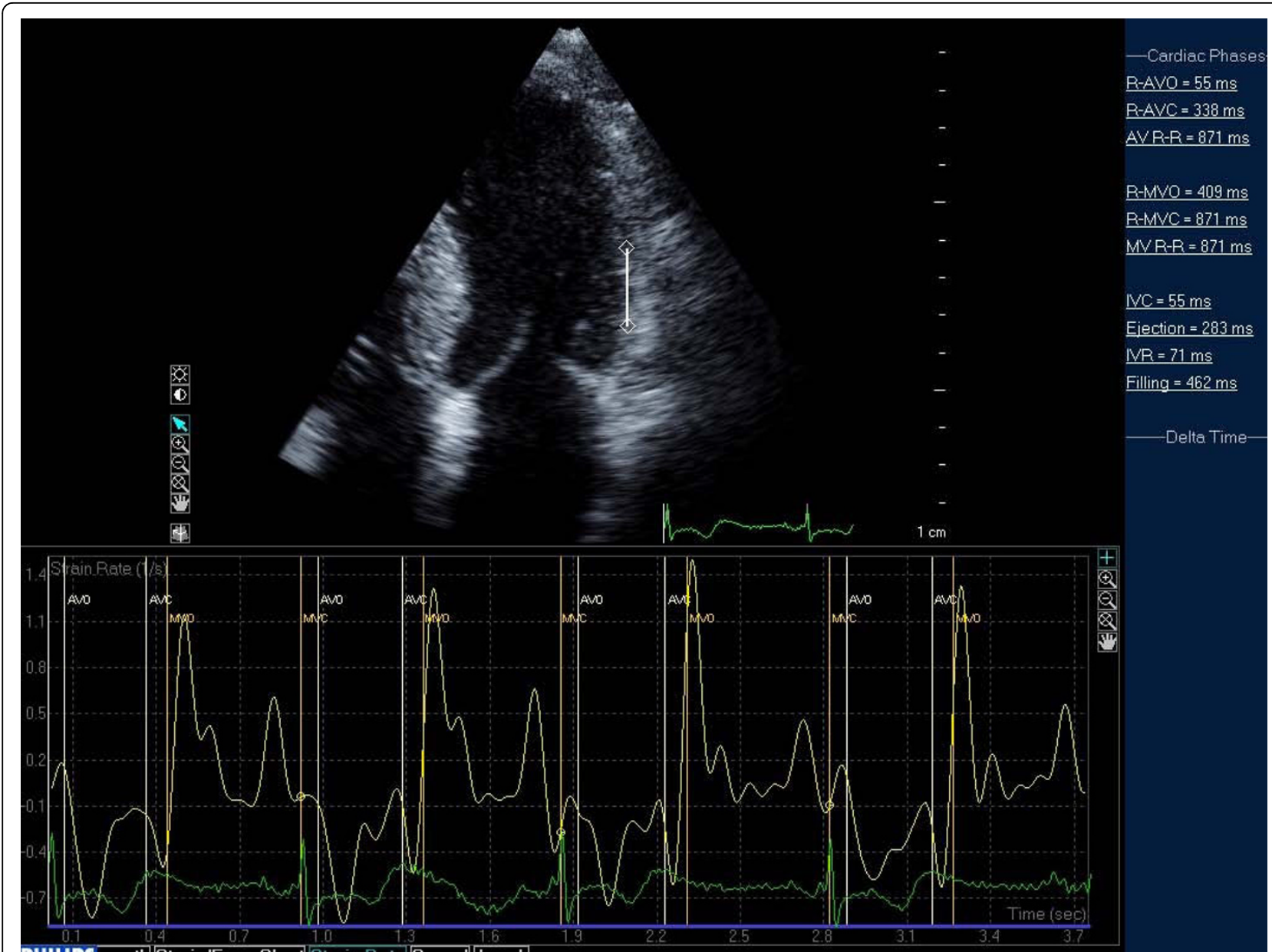

Figure 17 Example of post-systolic strain in a patient with HCM

\section{$M R I$}

MRI is an important imaging technique with an expanding role in the contemporary evaluation of patients with HCM; it provides complete LV reconstruction and a precise definition of the distribution and pattern of hypertrophy [78]. This is particularly useful in patients without a clear LV anatomic characterization by echocardiography. Measurements of MWT by echocardiography and by MRI are strictly related whereas MWT shows weak relationship when related to LV mass $[79,80]$.

In patients highly suspected to have HCM, but with a negative echocardiogram for LV hypertrophy, MRI represents an additive diagnostic chance as proposed by Rickers et al; Authors found, in a population involving almost 50 patients, that MRI was capable of identifying regions of LV hypertrophy (in particular at anterolateral level) not readily recognized by echocardiography, which were solely responsible for diagnosis of the HCM phenotype in an important minority of patients [81]. Moreover, the measure of LV mass and the characterization of abnormal substrate of fibrosis will probably provide implications of these findings in the risk stratification [81]. Nevertheless, it must be underscored that MRI doesn't provide complete LV tissue characterization and, thus, can not be used as a non-invasive biopsy.

\section{Genetic testing}

The diagnosis of HCM is most easily and reliably established by clinical and instrumental examination in the majority of affected adult patients. Thus, in patients with certain clinical diagnosis, genetic testing represents only a diagnostic confirmation. Nevertheless, molecular studies have the potential to enhance diagnostic reliability in HCM and can play an important role in resolving ambiguous diagnoses [82]. Moreover, in selected pedigrees genetic testing, has led to the identification of increasing numbers of children and adults with a preclinical diagnosis of HCM. These individuals have a disease-causing genetic mutation but no clinical or phenotypic manifestations of HCM. At present, there is no available evidence to justify precluding such 
genotype-positive, phenotype-negative individuals from most employment opportunities or life activities; however, a family history of frequent HCM-related death or the documentation of a particularly malignant genotype may justify efforts at risk stratification and possible restriction from competitive sports. Such a clinical scenario suggest that it is extremely important that family members receive careful counseling both before and after testing [83].

\section{Conclusion}

Two-dimensional echocardiography has been the most used, efficient and accessible technique for establishment of the diagnosis of HCM. Echocardiography can provide important information for the appropriate diagnosis and pathophysiological assessment of HCM patients. However, echocardiography alone can not differentiate different forms of unexplained LV hypertrophy. It must be underscore that its role is highlight only when is used after a complex clinical evaluation including familial and personal anamnesis, clinical examination, electrocardiogram, haemato-chemical tests.

\section{Author details \\ ${ }^{1}$ Department of Clinical Medicine, Cardiovascular and Immunological Sciences, University Federico II, Naples, Italy. ${ }^{2}$ CMSR Veneto Medica -Altavilla Vicentina, Italy. ${ }^{3}$ Department of Clinical and Experimental Medicine, University Federico II, Naples, Italy. ${ }^{4}$ Referral Center for Myocardial Diseases, Careggi University Hospital, Florence. ${ }^{5}$ Noninvasive Cardiology Unit, Ospedale San Raffaele, IRCCS, Milano, Italy. ${ }^{6}$ Cardiology Operative Unit, S. Maria Annunziata Hospital, Firenze, Italy. ${ }^{7}$ Department of Clinical Medicine, University of Pisa, Pisa, Italy. ${ }^{8}$ Chair of Cardiology, Second University of Naples, Naples, Italy. ${ }^{9}$ Azienda Ospedaliera Universitaria, Ferrara, Italy. ${ }^{10}$ Department of Cardiovascular, Respiratory and Morphological Sciences, University of Rome, University La Sapienza, Rome, Italy. ${ }^{11}$ Department of Cardiovascular Diseases, University of Siena, Italy.}

\section{Authors' contributions \\ MAL conceived the review and drafted the manuscript. SN e MG suggested the scheme of the review and revised critically the paper. SB revised critically the manuscript and added figures which resulted in a more readable manuscript. $\mathrm{FC}$ and $\mathrm{IO}$ revised critically the manuscript and gave important changes before the final submission. EA and PB performed a statistical analysis when necessary and revised critically part of the bibliography giving important criticism on the prognostic role of echo in patients with HCM. SB and ADA helped in the collection of the bibliography suggesting some important papers reported in the review and improved the chapters concerning the differential diagnosis in patients with HCM. ADE and DM contributed and improved the chapters concerning the role of new technologies. SS participated in the design of the review. SM participated in the design of the review and gave the final approval. All authors read and approved the final manuscript.}

\section{Competing interests}

The authors declare that they have no competing interests.

Received: 27 January 2010 Accepted: 17 March 2010

Published: 17 March 2010

\section{References}

1. Maron BJ, McKenna WJ, Danielson GK, Kappenberger LJ, Kuhn HJ, Seidman CE, Shah PM, Spencer WH, Spirito P, Ten Cate FJ, Wigle ED: ACC/
ESC clinical expert consensus document on hypertrophic cardiomyopathy: a report of the American College of Cardiology Task Force on Clinical Expert Consensus Documents and the European Society of Cardiology Committee for Practice Guidelines (Committee to Develop an Expert Consensus Document on Hypertrophic Cardiomyopathy). J Am Coll Cardiol 2003, 42:1687-713.

2. Maron BJ, Towbin JA, Thiene G, Antzelevitch C, Corrado D, Arnett D, Moss AJ, Seidman CE, Young JB: Contemporary definitions and classification of the cardiomyopathies. Circulation 2006, 113:1807-16.

3. Elliott $P$, Andersson $B$, Arbustini $E$, Bilinska Z, Cecchi F, Charron $P$, Dubourg O, Kühl U, Maisch B, McKenna WJ, Monserrat L, Pankuweit S, Rapezzi C, Seferovic P, Tavazzi L, Keren A: Classification of the cardiomyopathies: a position statement from the European Society Of Cardiology Working Group on Myocardial and Pericardial Diseases. Eur Heart J 2008, 29:270-6.

4. Doi YL, McKenna WJ, Oakley CM, Goodwin JF: 'Pseudo' systolic anterior motion in patients with hypertensive heart disease. Eur Heart J 1983, 4:838-45.

5. Pollick C, Rakowski H, Wigle ED: Muscular subaortic stenosis: the quantitative relationship between systolic anterior motion and the pressure gradient. Circulation 1984, 69:43-9.

6. Maron BJ, Edwards JE, Epstein SE: Prevalence and characteristics of disproportionate ventricular septal thicknening in patients with systemic hypertension. Chest 1978, 73:466-70.

7. Pieroni M, Chimenti C, De Cobelli F, Morgante E, Del Maschio A, Gaudio C, Russo MA, Frustaci A: Fabry's disease cardiomyopathy: echocardiographic detection of endomyocardial glycosphingolipid compartmentalization. J Am Coll Cardiol 2006, 47:1663-71.

8. Kounas S, Demetrescu C, Pantazis AA, Keren A, Lee PJ, Hughes D, Mehta A, Elliott PM: The binary endocardial appearance is a poor discriminator of Anderson-Fabry disease from familial hypertrophic cardiomyopathy. $J$ Am Coll Cardiol 2008, 51:2058-61.

9. Arad M, Maron BJ, Gorham JM, Johnson WH Jr, Saul JP, Perez-Atayde AR, Spirito P, Wright GB, Kanter RJ, Seidman CE, Seidman JG: Glycogen storage diseases presenting as hypertrophic cardiomyopathy. N Engl J Med 2005, 352:362-72.

10. Gottdiener JS, Hawley RJ, Maron BJ, Bertorini TF, Engle WK: Characteristics of the cardiac hypertrophy in Friedreich's ataxia. Am Heart J 1982, 103:525-31.

11. Nistri S, Olivotto I, Betocchi S, Losi MA, Valsecchi G, Pinamonti B, Conte MR, Casazza F, Galderisi M, Maron BJ, Cecchi F: Prognostic significance of left atrial size in patients with hypertrophic cardiomyopathy (from the Italian Registry for Hypertrophic Cardiomyopathy). Am J Cardiol 2006, 98:960-5.

12. Briguori $C$, Betocchi $S$, Losi MA, Manganelli F, Piscione F, Pace L, Boccalatte M, Gottilla R, Salvatore M, Chiariello M: Noninvasive evaluation of left ventricular diastolic function in hypertrophic cardiomyopathy. Am J Cardiol 1998, 81(2):180-7.

13. Briguori C, Betocchi S, Romano M, Manganelli F, Losi MA, Ciampi $Q$, Gottilla R, Lombardi R, Condorelli M, Chiariello M: Exercise capacity in hypertrophic cardiomyopathy depends on left ventricular diastolic function. Am J Cardiol 1999, 84:309-15.

14. Losi MA, Betocchi S, Aversa M, Lombardi R, Miranda M, D’Alessandro G, Cacace A, Tocchetti CG, Barbati G, Chiariello M: Determinants of atrial fibrillation development in patients with hypertrophic cardiomyopathy. Am J Cardiol 2004, 94:895-900.

15. Spirito P, Maron BJ, Chiarella F, Bellotti P, Tramarin R, Pozzoli M, Vecchio C: Diastolic abnormalities in patients with hypertrophic cardiomyopathy: relation to magnitude of left ventricular hypertrophy. Circulation 1985, 72:310-6.

16. Klues HG, Schiffers A, Maron BJ: Phenotypic spectrum and patterns of left ventricular hypertrophy in hypertrophic cardiomyopathy morphologic observations and significance as assessed by two-dimensional echocardiography in 600 patients. J Am Coll Cardiol 1995, 26:1699-708.

17. Monserrat L, Hermida-Prieto M, Fernandez X, Rodríguez I, Dumont $C$, Cazón L, Cuesta MG, Gonzalez-Juanatey C, Peteiro J, Alvarez N, PenasLado M, Castro-Beiras A: Mutation in the alpha-cardiac actin gene associated with apical hypertrophic cardiomyopathy, left ventricular non-compaction, and septal defects. Eur Heart J 2007, 28:1953-61.

18. Wigle ED, Sasson Z, Henderson MA, Ruddy TD, Fulop J, Rakowski H, Williams WG: Hypertrophic cardiomyopathy. The importance of the site 
and the extent of hypertrophy. A review. Prog Cardiovasc Dis 1985, 28:1-83.

19. Spirito $P$, Maron BJ: Relation between extent of left ventricular hypertrophy and occurrence of sudden cardiac death in hypertrophic cardiomyopathy. J Am Coll Cardiol 1990, 15:1521-6.

20. Spirito P, Bellone P, Harris KM, Bernabo P, Bruzzi P, Maron BJ: Magnitude of left ventricular hypertrophy and risk of sudden death in hypertrophic cardiomyopathy. N Engl J Med 2000, 342:1778-85.

21. Elliott PM, Gimeno Blanes JR, Mahon NG, Poloniecki JD, McKenna WJ: Relation between severity of left-ventricular hypertrophy and prognosis in patients with hypertrophic cardiomyopathy. Lancet 2001, 357:420-4

22. Olivotto I, Gistri R, Petrone P, Pedemonte E, Vargiu D, Cecchi F: Maximum left ventricular thickness and risk of sudden death in patients with hypertrophic cardiomyopathy. J Am Coll Cardiol 2003, 41:315-21.

23. Maron J, Spirito P: Implications of left ventricular remodeling in hypertrophic cardiomyopathy. Am J Cardiol 1998, 81:1339-44.

24. Niimura H, Bachinski LL, Sangwatanaroj S, Watkins H, Chudley AE, McKenna W, Kristinsson A, Roberts R, Sole M, Maron BJ, Seidman JG, Seidman CE: Mutations in the gene for cardiac myosin-binding protein $C$ and late-onset familial hypertrophic cardiomyopathy. N Engl J Med 1998, 338:1248-57.

25. Forissier JF, Charron $\mathrm{P}$, Tezenas du Montcel $\mathrm{S}$, Hagège $\mathrm{A}$, Isnard $\mathrm{R}$, Carrier $\mathrm{L}$, Richard P, Desnos M, Bouhour JB, Schwartz K, Komajda M, Dubourg O: Diagnostic accuracy of a $2 \mathrm{D}$ left ventricle hypertrophy score for familial hypertrophic cardiomyopathy. Eur Heart J 2005, 26:1882-6.

26. Biagini E, Coccolo F, Ferlito M, Perugini E, Rocchi G, Bacchi-Reggiani L, Lofiego C, Boriani G, Prandstraller D, Picchio FM, Branzi A, Rapezzi C: Dilated-hypokinetic evolution of hypertrophic cardiomyopathy: prevalence, incidence, risk factors, and prognostic implications in paediatric and adult patients. J Am Coll Cardiol 2005, 46:1543-50.

27. Harris KM, Spirito P, Maron MS, Zenovich AG, Formisano F, Lesser JR, Mackey-Bojack S, Manning WJ, Udelson JE, Maron BJ: Prevalence, clinical profile, and significance of left ventricular remodeling in the end-stage phase of hypertrophic cardiomyopathy. Circulation 2006, 114:216-25.

28. Spirito P, Maron BJ: Relation between extent of left ventricular hypertrophy and age in patients with hypertrophic cardiomyopathy. J Am Coll Cardiol 1989, 13:820-823.

29. Maron BJ, Casey SA, Hurrell DG, Aeppli DM: Relation of left ventricular thickness to age and gender in hypertrophic cardiomyopathy. Am J Cardiol 2003, 91:1195-98.

30. Topol EJ, Traill TA, Fortuin NC: Hypertensive hypertrophic cardiomyopathy in the elderly. N Eng J Med 1985, 312:277-83.

31. Niimura H, Patton KK, McKenna WJ, Soults J, Maron BJ, Seidman JG, Seidman CE: Sarcomere protein gene mutations in hypertrophic cardiomyopathy of the elderly. Circulation 2002, 105:446-51.

32. Kato TS, Noda A, Izawa H, Yamada A, Obata K, Nagata K, Iwase M, Murohara T, Yokota M, et al: Discrimination of nonobstructive hypertrophic cardiomyopathy from hypertensive left ventricular hypertrophy on the basis of strain rate imaging by tissue Doppler ultrasonography. Circulation 2004, 110:3808-14.

33. Kubo T, Gimeno JR, Bahl A, Steffensen U, Steffensen M, Osman E, Thaman R, Mogensen J, Elliott PM, Doi Y, McKenna WJ: Prevalence, clinical significance, and genetic basis of hypertrophic cardiomyopathy with restrictive phenotype. J Am Coll Cardiol 2007, 49:2419-26.

34. Leone O, Rapezzi C, Sinagra G, Angelini A, Arbustini E, Bartoloni G, Basso C, Caforio ALP, Calabrese F, Coccolo F, d'Amati G, Maresi E, Milanesi O, Nodali S, Oliva F, Perkan A, Prandstraller D, Pucci A, Ramando A, Silvestri F, Valente $M$, Thiene G: Documento di consenso sulla biopsia endomiocardica promosso dall'Associazione per la Patologia Cardiovascolare Italiana. G Ital Cardiol 2009, 10(Suppl 1-9):185-50S.

35. Cooper LT, Baughman KL, Feldman AM, Frustaci A, Jessup M, Kuhl U, Levine GN, Narula J, Starling RC, Towbin J, Virmani R, American Heart Association; American College of Cardiology; European Society of Cardiology: The role of endomyocardial biopsy in the management of cardiovascular disease: a scientific statement from the American Heart Association, the American College of Cardiology, and the European Society of Cardiology. Circulation 2007, 116:2216-33.

36. Sachdev B, Takenaka T, Teraguchi H, Tei C, Lee P, McKenna WJ, Elliott PM: Prevalence of Anderson-Fabry disease in male patients with late onset hypertrophic cardiomyopathy. Circulation 2002, 105:1407-11.
37. Groh WJ, Zipes DP: Neurological disorders and cardiovascular disease. Heart Disease. A textbook of cardiovascular medicine Philadelphia. Elsevier SaundersBranwald E, 72005.

38. Dubrey SW, Cha K, Skinner M, LaValley M, Falk RH: Familial and primary (AL) cardiac amyloidosis: echocardiographically similar diseases with distinctly different clinical outcomes. Heart 1997, 78:74-82.

39. Nistri S, Thiene G, Basso C, Corrado D, Vitolo A, Maron BJ: Screening for hypertrophic cardiomyopathy in a young male military population. Am J Cardiol 2003, 91:1021-3.

40. Corrado D, Basso C, Schiavon M, Pelliccia A, Thiene G: Pre-participation screening of young competitive athletes for prevention of sudden cardiac death. J Am Coll Cardiol 2008, 52:1981-9.

41. Pelliccia A, Maron BJ, Spataro A, Proschan MA, Spirito P: The upper limit of physiologic cardiac hypertrophy in highly trained elite athletes. $N$ Engl J Med 1991, 324:295-301.

42. Montgomery HE, Clarkson P, Dollery CM, Prasad K, Losi MA, Hemingway $H_{\text {, }}$ Statters D, Jubb M, Girvain M, Varnava A, World M, Deanfield J, Talmud P, McEwan JR, McKenna WJ, Humphries S: Association of angiotensinconverting enzyme gene I/D polymorphism with change in left ventricular mass in response to physical training. Circulation 1997, 96:741-7.

43. Basavarajaiah S, Boraita A, Whyte G, Wilson M, Carby L, Shah A, Sharma S: Ethnic differences in left ventricular remodeling in highly-trained athletes relevance to differentiating physiologic left ventricular hypertrophy from hypertrophic cardiomyopathy. J Am Coll Cardiol 2008, 51:2256-62.

44. Caso P, D'Andrea A, Caso I, Severino S, Calabrò P, Allocca F, Mininni N, Calabrò R: The athlete's heart and hypertrophic cardiomyopathy: two conditions which may be misdiagnosed and coexistent. Which parameters should be analyzed to distinguish one disease from the other? J Cardiovasc Med (Hagerstown) 2006, 7:257-66.

45. Nagueh SF, Mahmarian JJ: Noninvasive cardiac imaging in patients with hypertrophic cardiomyopathy. J Am Coll Cardiol 2006, 48:2410-22.

46. McKenna WJ, Kleinebenne A, Nihoyannopoulos P, Foale R: Echocardiographic measurement of right ventricular wall thickness in hypertrophic cardiomyopathy: relation to clinical and prognostic features. J Am Coll Cardiol 1988, 1:351-8.

47. Maron MS, Hauser TH, Dubrow E, Horst TA, Kissinger KV, Udelson JE, Manning WJ: Right ventricular involvement in hypertrophic cardiomyopathy. Am J Cardiol 2007, 100:1293-8.

48. Maron MS, Finley JJ, Bos JM, Hauser TH, Manning WJ, Haas TS, Lesser JR, Udelson JE, Ackerman MJ, Maron BJ: Prevalence, clinical significance, and natural history of left ventricular apical aneurysms in hypertrophic cardiomyopathy. Circulation 2008, 118:1541-9.

49. Sachdev V, Shizukuda Y, Brenneman CL, Birdsall CW, Waclawiw MA, Arai AE, Mohiddin SA, Tripodi D, Fananapazir L, Plehn JF: Left atrial volumetric remodeling is predictive of functional capacity in nonobstructive hypertrophic cardiomyopathy. Am Heart J 2005, 149(4):730-6.

50. Losi MA, Betocchi S, Aversa M, Lombardi R, Miranda M, Cacace A, Ciampi Q Tocchetti CG, Guida A, Chiariello M: Dobutamine stress echocardiography in hypertrophic cardiomyopathy. Cardiology 2003, 100:93-100.

51. Yu EH, Omran AS, Wigle ED, Williams WG, Siu SC, Rakowski H: Mitral regurgitation in hypertrophic obstructive cardiomyopathy: relationship to obstruction and relief with myectomy. J Am Coll Cardiol 2000, 36:2219-25.

52. Panza JA, Petrone RK, Fananapazir L, Maron BJ: Utility of continuous wave Doppler echocardiography in the noninvasive assessment of left ventricular outflow tract pressure gradient in patients with hypertrophic cardiomyopathy. J Am Coll Cardiol 1992, 19(1):91-9.

53. Maron MS, Olivotto I, Zenovich AG, Link MS, Pandian NG, Kuvin JT, Nistri S, Cecchi F, Udelson JE, Maron BJ: Hypertrophic cardiomyopathy is predominantly a disease of left ventricular outflow tract obstruction. Circulation 2006, 114:2232-9.

54. Shah JS, Esteban MT, Thaman R, Sharma R, Mist B, Pantazis A, Ward D, Kohli SK, Page SP, Demetrescu C, Sevdalis E, Keren A, Pellerin D, McKenna WJ, Elliott PM: Prevalence of exercise-induced left ventricular outflow tract obstruction in symptomatic patients with non-obstructive hypertrophic cardiomyopathy. Heart 2008, 94:1288-94.

55. Maron BJ, Mclntosh CL, Klues HG, Cannon RO, Roberts WC: Morphologic basis for obstruction to right ventricular outflow in HCM. Am J Cardiol 1993, 71:1089-94. 
56. Betocchi S, Bonow RO, Bacharach SL, Rosing DR, Maron BJ, Green MV: Isovolumic relaxation period in hypertrophic cardiomyopathy: assessment by radionuclide angiography. J Am Coll Cardiol 1986, 7:74-81.

57. Nagueh SF, Lakkis NM, Middleton KJ, Spencer WH, Zoghbi WA, Quiñones MA: Doppler estimation of left ventricular filling pressures in patients with hypertrophic cardiomyopathy. Circulation 1999, 99:254-61.

58. Lombardi R, Betocchi S, Losi MA, Tocchetti CG, Aversa M, Miranda M, D'Alessandro G, Cacace A, Ciampi Q, Chiariello M: Myocardial collagen turnover in hypertrophic cardiomyopathy. Circulation 2003, 108:1455-60.

59. Losi MA, Betocchi S, Chinali M, Barbati G, D'Alessandro G, Cacace A, Lombardi R, Contaldi C, de Simone G, Chiariello M: Myocardial texture in hypertrophic cardiomyopathy. J Am Soc Echocardiogr 2007, 20:1253-9.

60. Nagueh SF, Lakkis NM, He ZX, Middleton KJ, Killip D, Zoghbi WA, Quinones M, Roberts R, Verani MS, Kleiman NS, Spencer WH III: Role of myocardial contrast echocardiography during nonsurgical septal reduction therapy for hypertrophic obstructive cardiomyopathy. J Am Coll Cardiol 1998, 32:225-9.

61. Soman P, Swinburn J, Callister M, Stephens NG, Senior R: Apical hypertrophic cardiomyopathy: bedside diagnosis by intravenous contrast echocardiography. J Am Soc Echocardiogr 2001, 14:311-3.

62. Geske JB, Sorajja P, Nishimura RA, Ommen SR: Evaluation of left ventricular filling pressures by Doppler echocardiography in patients with hypertrophic cardiomyopathy: correlation with direct left atrial pressure measurement at cardiac catheterization. Circulation 2007, 4;116:2702-8.

63. Matsumura Y, Elliott PM, Virdee MS, Sorajja P, Doi Y, McKenna WJ: Left ventricular diastolic function assessed using Doppler tissue imaging in patients with hypertrophic cardiomyopathy: relation to symptoms and exercise capacity. Heart 2002, 87:247-51.

64. McMahon CJ, Nagueh SF, Pignatelli RH, Denfield SW, Dreyer WJ, Price JF, Clunie S, Bezold LI, Hays AL, Towbin JA, Eidem BW: Characterization of left ventricular diastolic function by tissue Doppler imaging and clinical status in children with hypertrophic cardiomyopathy. Circulation 2004 109:1756-62.

65. Nagueh SF, Chen S, Patel R, Tsybouleva N, Lutucuta S, Kopelen HA, Zoghbi WA, Quiñones MA, Roberts R, Marian AJ: Evolution of expression of cardiac phenotypes over a 4-year period in the beta-myosin heavy chain-Q403 transgenic rabbit model of human hypertrophic cardiomyopathy. J Mol Cell Cardiol 2004, 36:663-73.

66. Nagueh SF, McFalls J, Meyer D, Hill R, Zoghbi WA, Tam JW, Quiñones MA, Roberts R, Marian AJ: Tissue Doppler imaging predicts the development of hypertrophic cardiomyopathy in subjects with subclinical disease. Circulation 2003, 108(4):395-8.

67. Ho CY, Sweitzer NK, McDonough B, Maron BJ, Casey SA, Seidman JG, Seidman CE, Solomon SD: Assessment of diastolic function with Doppler tissue imaging to predict genotype in preclinical hypertrophic cardiomyopathy. Circulation 2002, 105(25):2934-6.

68. Betocchi S, Hess OM, Losi MA, Nonogi H, Krayenbuehl HP: Regional left ventricular mechanics in hypertrophic cardiomyopathy. Circulation 1993 88:2206-14.

69. Ganame J, Mertens L, Eidem BW, Claus P, D'hooge J, Havemann LM, McMahon CJ, Elayda MA, Vaughn WK, Towbin JA, Ayres NA, Pignatelli RH: Regional myocardial deformation in children with hypertrophic cardiomyopathy: morphological and clinical correlations. Eur Heart $J$ 2007, 28(23):2886-94

70. Weidemann F, Niemann M, Herrmann S, Kung M, Störk S, Waller C, Beer M, Breunig F, Wanner C, Voelker W, Ertl G, Bijnens B, Strotmann JM: A new echocardiographic approach for the detection of non-ischemic fibrosis in hypertrophic myocardium. Eur Heart J 2007, 28:3020-6.

71. Notomi Y, Setser RM, Shiota T, Martin-Miklovic MG, Weaver JA, Popovic ZB, Yamada H, Greenberg NL, White RD, Thomas JD: Assessment of left ventricular torsional deformation by Doppler tissue imaging: a validation study using tagged magnetic resonance imaging. Circulation 2005, 111:1141-1147.

72. Notomi Y, Martin-Miklovic MG, Oryszak SJ, Shiota T, Deserranno D, Popovic ZB, Garcia MJ, Greenberg NL, Thomas JD: Enhanced ventricular untwisting during exercise: a mechanistic manifestation of elastic recoil described by Doppler tissue imaging. Circulation 2006, 113:2524-33.

73. Wang J, Buergler JM, Veerasamy K, Ashton YP, Nagueh SF: Delayed untwisting: the mechanistic link between dynamic obstruction and exercise tolerance in patients with hypertrophic obstructive cardiomyopathy. J Am Coll Cardiol 2009, 54:1326-34.
74. Sun JP, Stewart WJ, Yang XS, Donnell RO, Leon AR, Felner JM, Thomas JD, Merlino JD: Differentiation of hypertrophic cardiomyopathy and cardiac amyloidosis from other causes of ventricular wall thickening by twodimensional strain imaging echocardiography. Am J Cardiol 2009, 103:411-5.

75. Lazzeroni E, Picano E, Morozzi L, Maurizio AR, Palma G, Ceriati R, lori E, Barilli A: Dipyridamole-induced ischemia as a prognostic marker of future adverse cardiac events in adult patients with hypertrophic cardiomyopathy. Echo Persantine Italian Cooperative (EPIC) Study Group, Subproject Hypertrophic Cardiomyopathy. Circulation 1997, 96:4268-72.

76. Cecchi F, Olivotto I, Gistri R, Lorenzoni R, Chiriatti G, Camici PG: Coronary microvascular dysfunction and prognosis in hypertrophic cardiomyopathy. N Engl J Med 2003, 349:1027-35.

77. Cortigiani L, Rigo F, Gherardi S, Galderisi M, Sicari R, Picano E: Prognostic implications of coronary flow reserve on left anterior descending coronary artery in hypertrophic cardiomyopathy. Am J Cardiol 2008 102:1718-23.

78. Maron MS: The current and emerging role of cardiovascular magnetic resonance imaging in hypertrophic cardiomyopathy. J of Cardiovasc Trans Res 2009, 2:415-25.

79. Romano R, Losi MA, Migliore T, Contaldi C, Parrella LS, Caputi A, Betocchi S: Evaluation of the left ventricular anatomy in hypertrophic cardiomyopathy: comparison between echocardiography and cardiac magnetic resonance imaging. Minerva Cardioangiol 2008, 56:181-7.

80. Olivotto I, Maron MS, Autore C, Lesser JR, Rega L, Casolo G, De Santis M, Quarta G, Nistri S, Cecchi F, Salton CJ, Udelson JE, Manning WJ, Maron BJ: Assessment and significance of left ventricular mass by cardiovascular magnetic resonance in hypertrophic cardiomyopathy. J Am Coll Cardiol 2008, 52:559-66.

81. Rickers C, Wilke NM, Jerosch-Herold M, Casey SA, Panse P, Panse N, Weil J, Zenovich AG, Maron BJ: Utility of cardiac magnetic resonance imaging in the diagnosis of hypertrophic cardiomyopathy. Circulation 2005, 112:855-61.

82. Maron BJ, Moller JH, Seidman CE, Vincent GM, Dietz HC, Moss AJ, Towbin JA, Sondheimer HM, Pyeritz RE, McGee G, Epstein AE: Impact of laboratory molecular diagnosis on contemporary diagnostic criteria for genetically transmitted cardiovascular diseases: hypertrophic cardiomyopathy, Long-QT Syndrome, and Marfan Syndrome. Circulation 1998, 98:1460-1471.

83. Colombo MG, Botto N, Vittorini S, Paradossi U, Andreassi MG: Clinical utility of genetic tests for inherited hypertrophic and dilated cardiomyopathies. Cardiovasc Ultrasound 2008, 19:6-62.

doi:10.1186/1476-7120-8-7

Cite this article as: Losi et al:: Echocardiography in patients with hypertrophic cardiomyopathy: usefulness of old and new techniques in the diagnosis and pathophysiological assessment. Cardiovascular Ultrasound 2010 8:7.

\section{Submit your next manuscript to BioMed Central and take full advantage of:}

- Convenient online submission

- Thorough peer review

- No space constraints or color figure charges

- Immediate publication on acceptance

- Inclusion in PubMed, CAS, Scopus and Google Scholar

- Research which is freely available for redistribution 